Sebastiáo André de Fêlice

\title{
COMPLEXO HOSPITALAR DO MANDAQUI HOSPITAL DE CLÍNICAS DA ZONA NORTE DO MUNICIPIO DE SÃO PAULO
}

\begin{abstract}
Dissertaçāo apresentada à Faculdade de Saúde Pública da Universidado de São Paulo (Departamento de Prática de Saúde Pública, Disciplina Administraçāo Hospitalar) para obtenção do título de MESTRE em Saúde Pública
\end{abstract}

Orientadora: Profa. Dra. Lourdes de Freitas Carvalho

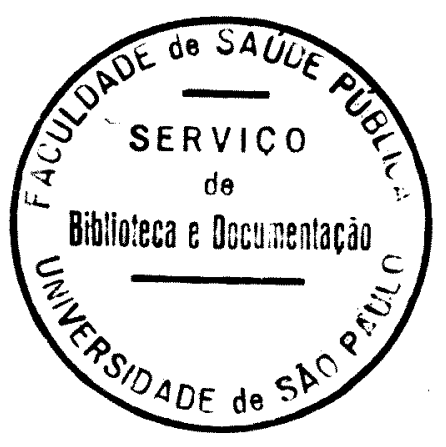

SÃO PAULO

1984 
AGFADECTIEITIOS

A Profe. Dra. LOURDES DE FREITAS CAFUALHO pelo incentivo, amizade e orie tefão nas minhas atividades profissinneis.

A todos que, direta ou indiretemente, roo peraram na elaborarão deste trahalho. 
A memória de meu pai, VTCENTE DE FELICE, que em toda sua existência sempre me ori entou para a vida com amor e amizade. Amigo.

A minha mãe, kiARIA CONCEICÃC, exemplo de mulher que na sua modéstia, caráter, per sonalidade e amor é a responsável pelo que sou.

A minha esposa MAPIA CECILIA, meus fi Ihos ANDFEA, CYNTHIA, RENATA E MAFCELO, agradero a compreensão e ajuda que só existe numa família unida. 
RESUMO $\ldots \ldots \ldots \ldots \ldots \ldots \ldots \ldots \ldots \ldots \ldots \ldots \ldots \ldots \ldots \ldots \ldots \ldots \ldots \ldots$

SUMARY $\ldots \ldots \ldots \ldots \ldots \ldots \ldots \ldots \ldots \ldots \ldots \ldots \ldots \ldots \ldots \ldots \ldots \ldots \ldots \ldots \ldots \ldots$

1. INT RDDUCAO $\ldots \ldots \ldots \ldots \ldots \ldots \ldots \ldots \ldots \ldots \ldots \ldots \ldots \ldots \ldots$

2. DBปTIVO $\ldots \ldots \ldots \ldots \ldots \ldots \ldots \ldots \ldots \ldots \ldots \ldots \ldots \ldots \ldots \ldots \ldots$

3. PAFQUUE HOSPITALAR DO VANDAGUI $\ldots \ldots \ldots \ldots \ldots \ldots \ldots \ldots \ldots$

4. HOSPITAL INIFANTIL DA ZONA NOFTE ............... 12

5. ALGULAS CAFACTERISTILAS POPULACIONAIS E SÚCIO ECONOMI CAS DO MUIICIPIO DE SAOO PAULO E DOS DISTFITOS DE TUCURU

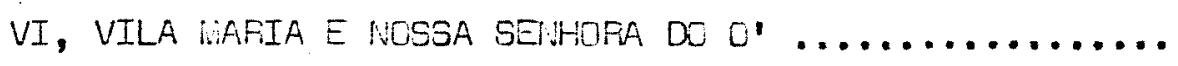

6. ALGUNS INDICADGFES DE SAÚde NA CIDADE dE SÃ̃ PAULO E FEGIAO NOFTE, DISTFITOS DE TUCURUVI, VILA NARIAE FFE

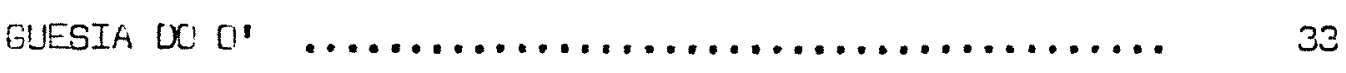

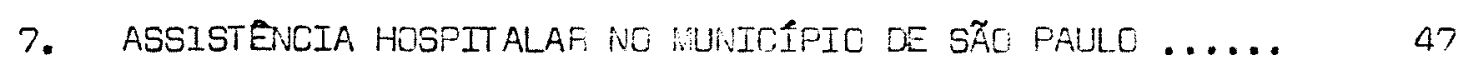

8. NECESSIDADE DE LEITOS HOSPITALAFES GEPAIS NOS DISTPITOS DE TUCURUVI, VILA MARIA E FFESUESIA DO $0 . \ldots \ldots \ldots \ldots . . .48$

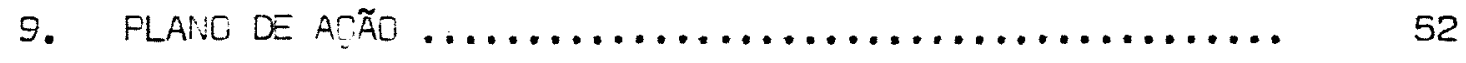

10. COMPLEXO HOSPITALAR DO MANDAQUI. INTEF-RELAÇŨES COM outros serviģos de saúde $\ldots \ldots \ldots \ldots \ldots \ldots \ldots \ldots \ldots \ldots$

11. CRONGGPA::A DE II:PLANTAGÃO DO COMPLEXO HCGPITALAF DO I:AN

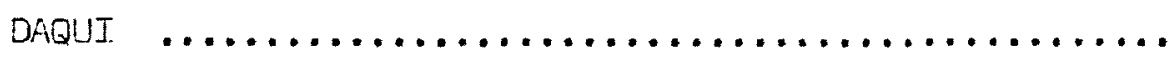

12. ESTRUTUPA ORGANIZACIONAL DO COMPLEXO HCGFITALAF: DO WAN DAQUI

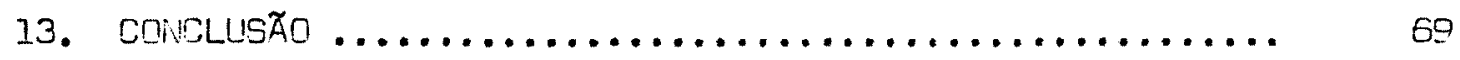

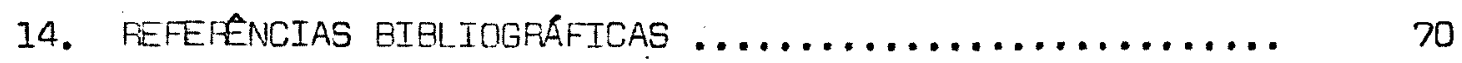

15. BIBLIOGRAFIAS CONSULTADAS $\ldots \ldots \ldots \ldots \ldots \ldots \ldots \ldots \ldots \ldots \ldots$. 71 
RESUMO

- objetivo da dissertação é descrever e analisar uma experiência em estabelecer um hospital geral de 750 leitos, a par tir de 2 hospitais previamente exis centes na região ilorte da Cidade de São Paulo.

Este estudo contempla o processo decisório em se criar um novo Hospital levando en conta ns critérios haseados nos conceitos de regionalização e hierarquização do sistema de assis tência ̀̀ Saúde. 
The objective of this dissertation is to describe and to analyse an experience of developing a general hospital of 750 beds from two old ones in the North section of the são Paulo City.

This study contemplates the decision making process to create the new Hospital, taking into account a set of criteria based on the concepts of regionalization and hierarchization of the health delivery system. 
O Parque Hospitalar do liandaqui, inaugurado em 1938, per tencente à Secretaria de Estado da Saúde, teve, ao Iongo de sua existên cia, participação ativa na luta contra a tuberculose. Vivenciou todas as modificações havidas com a doenca, decorrentes da evolução médico-socí al ocorridas nos últimos 45 anos.

Conta atualmente com 2 Pavilhões de internação: ○ Pavi Thão Leonor liendes de Barros, destinado à Pediatria e o Pavilhão Wiguel Pereira para intemação de pacientes adultos, ambos especializados no aten dimento da tuberculose.

Como um dos hospitais vanguardeiros na assistência do pa ciente tísico, atingiu renome estadual, nacional $E$ intemacional, princi palmente pela qualidade do atendimento prestado e excelente desenvolvimen to técnico-científico alcançado pela cirurgia torácica praticada no Hospi tal.

Na última década, o farque Hospitalar do liandaqui começou a sofrer um processo de desativação lenta e progressiva, onde a liberação de recursos necessários à sua manutenção encontrava sérias dificuldades de obtenção e a justificativa técnico-politica dada era a menor necessida de de leitos para intemação do tuberculoso, já que, a assistência ao mes mo passava a ser predominantemente ambulatorial.

0 Hospital Infantil da Zona Norte teve iniciado suas ati vidades em 1972, após reformas de adaptaçẽo no local onde anteriormente funcionava o Hospital Adhemar de Barros, responsável pela internação de pa cientes portadores de Pênfigo Foliáceo. Como Hospital estatal sempre en controu inúmeras dificuldades na obtenção de recursos, inviabilizando as pirações, projetos e ampliações assistenciais. Porém, dentro das possibi lidades oferecidas, mercê da atuação dedicada e qualificada da maioria do pessoal médico e para-médico, pôde prestar excelentes serviços à comuni dade infantil da Zona Norte. 
Assim sendo, encontrava-se no Hospital Infantil da Zona Norte uma situação que se assemelhava ao do Parque Hospitalar do liandaqui, onde leitos hospitalares públicos estavam desativados ou ociosos e, portan to, disponiveis.

- Parque Hospitalar do liandaqui e o Hospital Infantil da Zona Norte, subordinados à Coordenadoria de Assistência Hospitalar da Se cretaria de Saúde de São Paulo, contíguos em suas áreas físicas, delimita dos apenas e tão sómente por uma murada que separa os 2 Hospitais, têm suas estrutures administrativas e organizacionais totalmente distintas e com total ausência de coordenaçãa entre as mesmas. A discussão e redefi nição do papel desses Hospitais na estrutura de saúde existente na Zona Norte do hunicipio de são Paulo se impõe.

Foi através do I Forum de Debates sobre Recursosde Saúde da Zona Norte, realizada em abril de 1983, patrocinado pelos Hospitais In fantil da Zona Norte, Farque hospitalar do liandaqui e Coordenadoria de As sistência Hospitalar, que, conjuntamente, profissionais de saúde e popula ção, discutiram amplamente a problemática de Saúde desta região e, em ccparticipação com os docentes da cadeira de Administrąão Hospitalar da Fä culdade de Saúde Pública se concluiu efetivamente pela necessidade de in tẹração e mudança das finalidades dos 2 Hospitais.

Situados na Zona Norte do Vunicipio de São Faulo, área de indice demogréfico elevado, e com poucos recursos hospitalares gerais, de veriam os mesmos se integrarem, serem devidamente redimensionados, equipa dos e preparados para dar à população local a assistência que realmente ne cessita, alérn de manter e melhorar as condições assistenciais ao tuberculo so dentro de padrões técnicos atualizados e adequados.

Como Diretor Técnico designado para o hospital Infantil de Zona Norte e Parque Hospitaler do landaqui e docente de Administração Hospitalar da Faculdade de Saúde Pública, iniciemos então. a coordenação do projeto, que visa o levantamento da situação dos Hospitais, o diacnóstico, a ariálise, a mobilização de recursos, que possam viabilizar a intecracão e consequente implantação do Complexo Hospitalar do Mandaqui. 
2. DEJETIVD

Propor um modelo de integraçãó dos Hospitais Infantil da Zona Norte e Paraue Hosnitalár do handaqui, da Coordenadoria de Assis tência Hospitalar da Secretaria de Estado da Saúde, de finalidades distin tas, atualmente com alta ociosidade em suas capacidades operacionais, uti lizando os recursos fïsicos, humanos e financeiros existentes, visando a transformação dos mesmos em um Complexo Hospitalar de 750 leitos, o Comple xo Hospitalar do hiandaqui. 
- Parque Hospitalar do liandaqui está situado à Rua Volun tários da Pátria, no 4.301, Bairro do Mandaqui, Distrito Sanitário de Tucu ruvi.

E um dos hospitais estatais, subordinado ao Departamento de Hospitais Gerais e Especiais da Coordenadoria de Assistência Hospitalar da Secretaria de Saúde do Estado de São Paulo.

\section{FINALIDADES DO HOSPITAL}

Através do Decreto Govemamental no 52.530, de 17 de SE tembro de 1970, foi aprovado o Pegulamento do Parque Hospitalar do lianda qui, que prevê as sęuintes finalidades:

I - prestar assistência rédico-hosnitalar a pacientes portadores de tuberculose, de pneumopatias não especificas e de doenças in tercorrentes;

II - servir de campo de ensino e treinamento para estu dantes de ledicina, de Enfermagem, de Serviço Social hédico, de Nutrição e Dietética, de Administracão Hospitalar e de outras atividades ligadas à saú de;

III - servir de campo de aperfeicoamento para médicos, enfermeiros e nessnal hospitalar;

IV - proporcionar meios à investigação e à pesquisa;

$\checkmark$ - contribuir para a educac̃o sanitária; $e$

VI - proporcionar meios para reabilitação dos incapa citados.

Inaugurado em 27 de setembro de 1938, o Parque Hospitalar do llandaqui era inicialmente constituido de favilhões, com as seguintes de nominações, respectivas distribuições de leitos e data de inaugurações: 


\begin{tabular}{l|r|r}
\hline Denominações dos Pavilhões & No de Leitos & Data Ineuguração \\
\hline liandaqui I & 36 leitos & $01 / 12 / 1938$ \\
l.andaoui II & 42 leitos & $01 / 12 / 1938$ \\
l.andaqui III & 08 leitos & $01 / 12 / 1938$ \\
Leonor Viendes de Earros & 196 leitos & $25 / 12 / 1939$ \\
Antonio Alvaro Guião & 82 leitos & $20 / 06 / 1941$ \\
Nossa Senhora des Graças & 57 leitos & $25 / 12 / 1947$ \\
Wiguel Pereira & 446 leitos & $02 / 04 / 1950$
\end{tabular}

Foi, portanto, em 1939, com a inauguração do Pavilhão Leonor liendes de Earros, próprio para o aEendimento infantil, que o Hospi tal começou a melhor desenvolver a assistência à criança tuberculosa. E, em 1950, com o início das atividades do Pavilhão Niguel Pereira em prédio monobloco, construido dentro de padrões técnicos da assistência hospita lar, foram colocados 446 leitos em funcionemento, permitindo uma centrali zação das atividades de intemação na assistência médica prestada aos paci entes adultos portadores de tuberculose.

o Farque hospitalar do iandaqui teve então, a partir de 1950, praticamente toda intemação de pacientes centrada no Pavilhão Leonor hendes de Barros, para crianças e o Pavilhão higuel Pereira para pacientes adultos.

Basicamente, o funcionamento dos citados pavilhões obe deceram às seguintes distribuições quanto ès finalidades de uso das suas áreas físicas e adequação de número de leitos: 


\begin{tabular}{|c|c|c|c|}
\hline \multirow{2}{*}{ 10 ANDAR } & Ala $B$ & $\begin{array}{l}\text { Ia Clínica Pediátrica } \\
\text { ( Meninos e heninas de } 3 \text { a } 6 \text { anos ) }\end{array}$ & 29 leitos \\
\hline & Ala D & $\begin{array}{l}\text { 2a Clínica Pediátrica } \\
\text { ( Vieninos de } 6 \text { a } 14 \text { anos ) }\end{array}$ & 25 Ieitos \\
\hline \multirow{2}{*}{20 ANDAR } & Ala $B$ & $\begin{array}{l}\text { 3a Clínica Pediátrica } \\
\text { ( fieninas de } 6 \text { a } 14 \text { anos ) }\end{array}$ & 29 Ieitos \\
\hline & Ala D & $\begin{array}{l}\text { 4a Clinica Pediátrica } \\
\text { ( de } 0 \text { a } 3 \text { anos ) }\end{array}$ & 36 leitos \\
\hline \multirow{2}{*}{30 ANDAF } & Ala B & Clausura & - \\
\hline & Ala D & $\begin{array}{l}\text { 5a Clínica Pediátrica } \\
\text { ( Triagem ) }\end{array}$ & 19 leitos \\
\hline
\end{tabular}




\begin{tabular}{|c|c|c|c|}
\hline \multirow{2}{*}{20 ANDAF } & Ala B & İ Clínica l.édica lasculina. & 47 leitos \\
\hline & Ala D & 2E Clínica lédica lasculina. & 47 leitos \\
\hline \multirow{2}{*}{30 ANDAR } & Ala B & IE Clinica Cinúrgica lesculina. & 44 leitos \\
\hline & Ala D & 1日 Clínica Cirúrgica Feminina. & 37 leitos \\
\hline \multirow{2}{*}{ 40 ANDAF } & Ala B & 3a Clínica lérjica lasculina. & 44 leitos \\
\hline & Ala D & $\begin{array}{l}\text { 2e Clinica Cinúrgica Feminina. } \\
\text { ( Toco-Ginecológico) } \\
\text { Centro Ubstétrico. } \\
\text { Berçário }\end{array}$ & 30 leitos \\
\hline \multirow{2}{*}{ 50 ANDAR } & Ala $B$ & 4a Clínica Hédica Masculina. & 49 leitos \\
\hline & Ala D & 1a Clínica lédica Feminina. & 47 leitos \\
\hline \multirow{2}{*}{ G@ ANDAF } & Ala $B$ & $\begin{array}{l}\text { 5a Clínica lédica l'asculina. } \\
\text { ( Pneumopatias não Tuberculosas) }\end{array}$ & 30 leitos \\
\hline & Ala D & $\begin{array}{l}\text { za Clínica Védica Feninina. } \\
\text { ( Pneumopatias não Tuberculosas) }\end{array}$ & 32 leitos \\
\hline
\end{tabular}


- Perque Hospitalar do Nandaqui funcionava, portanto, com 545 leitos em seu total, distribuidos do seguinte modo conforme faixa etá ria, sexo e especialidade clínica ou cinúrgica.

Leitos Clínicos

Homens

liulheres

Criancias

Total

Total Geral de Leitos $=545$
Leitos Cinúroicos Homens 44

Mulheres

Total

Na última década, por uma política assistencial hospita lar que não priorizava o atendimento ao tuberculoso internado, mas sim estimulava o atendinento ambulatorial, a assistência prestada pelo Hospi tal foi-se tomando decrescente em qualidade e quantidade, sendo impos sivel mantê-la nos padrões técnicos e científicos anteriormente alcança dos, apesar da abnegação do grupo de médicos e funcionários dedicados.

No Parque Hospitaler do liandaqui, entretanto, o que sem pre foi observado foi a necessiciade constante de leitos hospitalares para adultos, principalmente do sexo masculino.

E um hospital de referência no atendimento dos pacientes tuberculosos, sendo o centralizador da assistência prestada não só da pa tologia específica, mas também de todas as intercorrências clinicas e ci rúrgicas do paciente tísico. Assim é que constantemente e continuamen te recebe pacientes vindos de outros nosocômios, particulamente de ou tros hospitais estatais com as mesmas finalidades como são o Hospital Nestor Goulart Reis de Américo Brasiliense e Hospital Aimorés de Bauru, ambos pertencentes à Secretaria de Saúde de São Paulo.

Nos últimos anos, com refomas iniciadas mas não termina das na estrutura física de uma das alas do Pavilhão Miguel Pereire, ocor reu uma redução na capacidade operacional de 446 para 233 leitos. Conco mitantemente foi se observando progressivamente redução na admissão de 
nessnal médico e de enfermanem, insuficientes recursos na área complemen tar de diagnóstico e terapêutica predoninando escassez de operadores de PX, auxiliares de laboratório e bioquímicos, trazendo prejuizos na as sistência prestada. Como consequência principal, a rotação de pacien tes foi se tornando mais lenta e a porcentagem de ocupação atinge níveis de $110 \%$ a $115 \%$ com pacientes ocupando corredores e refeitórios.

For outro lado, principalmente por falta de deman da, o Pavilhão Leonor liendes de Earros, que passou por reformas na sua área física em 1975 e é adequado para um total de 196 leitos, vinha ope rendo com cerca de 56 leitos e desses apenas eram ocupados aproxinadamen te 35 leitos. Desses 35 leitos, o observado era que em aproxinadamen te $50 ;$ os pacientes estavam intemadas por fatores sociais e patológicas e não devido a possibilidade de contágio que poderiam causar.

Em abril de 1983, após levantamento da situação dos Pavilhões liiguel Pereira e Leonor llencies de Barros foi encontrada a se guinte distribuição de leitos em funcionamento:

PAVILHÃO VIIGUEL PEREIFA

\begin{tabular}{l|l|l|r}
\hline 2o Andar & Ala B & Ia Clínica Médica hasculina & 63 leitos \\
\hline 30 Andar & Ala B & Ia Clínica Cinúrgica Nasculina & 32 leitos \\
\hline 40 Andar & Ala B & Ia Clínica lédica Feminina & 49 leitos \\
\hline 50 Andar & Ala B & 2a Clinica Védica Viasculina & 57 leitos \\
\hline 60 Andar & Ala B & 2a Clínica Védica Feminina & 32 leitos \\
\hline
\end{tabular}




\begin{tabular}{l|l|l|c}
\hline I0 Andar & Ala A & la Clínica Pediátrica liasculina & 28 leitos \\
\cline { 2 - 4 } & Ala B & Ia Clínica Pediátrica Feminina & 28 leitos \\
\hline & Total & 56 leitos \\
\hline
\end{tabular}

Pelo demonstrado, conclui-se que encontramos atualmente no Farque Hospitalar do landaqui, referência no atendimento hospitalar da tuberculose no Estado de São Paulo, a seguinte situaşão:

a-) o Pavilhão Leonor hendes de Barros tem grande número de leitos desativados $e$, os que estão em operação são além das necessida des de demanda e, portanto, ociosos.

Ł-) o Pavilhão Niquel Pereira tem $50^{\prime}$ : de seus leitos desa tivados em aguardo de reformas, alta média de permanência, alta porcenta gem de ocunação, inadequados e precários recursos laboratoriais e radio lógicos, junto com pessoal médico e para-médico em número insuficiente, desmotivados e insatisfeitos. 
o Hopital Infantil da Zona Norte está situado à Fua Augusto Tolle no 978, Bairro do Mandaqui, Distrito Sanitário de Tucuruví.

E um hospital estatal, subordinado ao Departamento de Hospi tais Gerais e Especiais da Coordenadoria de Assistência Hospitalar da Se cretaria de Estado da Saúde de São Paulo.

Foi criado por Decreto Governamental ñ 52.900, de 17 de março de 1972, que, em seu artigo 30 diz: "O Hospital Infantil da Zona Norte prestará essistência médico-hospitalar à populacão infantil, bern co mo teré as demais finalidades comuns aos Hosnitais da Coordenadoria de As sistência Hospitalar, previstas no Decreto ne 52.529 de 17 de setembro de 1970, e se instalaré no atual Edifício do Hospital Adhemar de Barros, na Capital ".

0 Decreto no 52.529 , de 17 de setembro de 1970, artigo 30, diz: "As unidades de assistência médico-hospitalar, de Coordenadoria de Assistência Hospitalar, têm por firalidades comuns:

I - prestar assistência médico-hospitalar dentro cas pos sibilidades técnicas e econômicas;

II - servir de campo de ensino e treinemento para estudan te de liedicina, de Eniemagem, de Serviço Social hiédico, de Nutrição e Dietética, de Administração Hospitalar e de outras atividades ligadas à saúde;

III - servir de campo de aperfeiçoamento para médicos, en fermeiros e pessoal hosoitalar;

$$
\begin{aligned}
& \text { IV - proporcionar meios à investigacão e à pesquisa; } \\
& V \text { - contribuir para a educação sanitária; } \\
& V I \text { - proporcionar meios para reabilitacão dos incapacita }
\end{aligned}
$$

dos.

0 Hospital Infantil da Zona Norte se instalou no Edifício do Hosnital Adhemar de Barros, conhecido como "Hospital do Penfigo Folié 
ceo ". Ainda en seu artigo 40, esse decreto previa a transferência do Hospital Adhemar de Barros para o liunicipio de Guarulhos, no Edifício situado à Avenida Emílio Ribas.

o Hospital entẽo criado objetivava melhorar a deficiên cia de leitos hospitalares para atender a população infantil da Zona Norte da cidade de São Paulo, uma das regiões carentes da Capital quan to a leitos pediátricos.

O aludido Hospital tinha sua capacidade operacional esti mada ern 400 leitos, distribuidos por 2 blocos: A e C. Cade bloco com 2 endares e cada andar com 2 alas, constituindo, portanto, 4 unidades de internargão.

lunto à área destinada ao Pronto Atendimento no andar térreo, existia uma unidade de intemação, com 35 leitos.

A distribuição dos leitos pelas unidades tinha a seguin te disposição:

B!OCO "A "

\begin{tabular}{|c|c|c|c|}
\hline Térreo & & Pronto Atendimento - Enfermaria & 35 leitos \\
\hline \multirow{2}{*}{ Io Andar } & Ala $A$ & Lactentes & 50 leitos \\
\hline & Ala $E$ & Lactentes & 50 Ieitos \\
\hline \multirow{2}{*}{$2^{\circ}$ Andar } & Ala A & Lactentes & 50 leitos \\
\hline & Ala B & Pré-Escolar - Escolar. & 50 Ieitos \\
\hline
\end{tabular}




\begin{tabular}{|c|c|c|c|}
\hline \multirow{2}{*}{ Is Andiar } & Ala $A$ & l.ectentes & sn leitos \\
\hline & Ala B & Lactentes & 50 1fitas \\
\hline \multirow{2}{*}{20 Anciar } & Ala $A$ & $L=0$ tentes & $5070 \cos$ \\
\hline & Ala $\mathrm{B}$ & Pré-Escolar - Escolar & 50 leitos \\
\hline
\end{tabular}

A ativação dos leitos nas unidades de intemarão não foi iniciada em coda sua plenitude cesde o início de funcionarnonlo do liospi tel, was sim paulatinanente, dependendo dos recursos itirariceires, de pes soal e equipanento que, gradativamente e precerianente, foram formoides pelo Eoverno do Estado de Gão Feulo.

Assim é que, en agosto de ISp2 entrou em funcioramento o Pronto Atendiriento e una Enífmaria de 35 leitos no andar térreo.

En 1973, a Fia A. do I andiar fermitiu, com seu funcionanen to, a anpliação de mais 40 leitos e o Hospittal já operava então com 75 Ieitos.

En 1974, com a ativação da bla $B$ do 10 endar e as alas A e E do zo andar, a capacidacie operecional já atingia 235 leitos.

Devido à epideria de meningite, ccorrida em São Paulo, em 1975, sem estar convenientenente preparado e sem nenhuma reforma de ada ptezäa, entrou en funcionariento o bloco C, com 200 leitos servindo de re taguarda ao Hospital Enílio fibas, no atendimento a pacientes portadores de meningite.

No final de 1976, com a diminuicão da incidência de menin 
gite, o Hospital teve reduzido o seu número de leitos operacionais para 200, compreendendo o andar Térreo e os 10 e 20 andares do Bloco A, mais 10 leitos de observação no Pronto Atendimento.

En 1977, com a reforma ocorricia no Bloco C, e nova adequa ção de leitos, o Hospital passou a ter a sua capacidade operacional esti mada em 350 leitos.

Durante sua evolução histórica assistencial, o hospital nunca teve populacão intemada que atingisse $80^{\prime}$ de ocupação.

Funcionou sempre, fundenentalmente, em função da sua ati vidade de Pronto A.tendimento de cascs clínicos pediátricos, já que inexis tia ativiciacie ambulatorial. Desde o início o Pronto Atendimento conse guiu grande demenda, sendo que, progressivamente, o seu atendimento atin giu 200 a 250 casos diários.

For outro lado, recebia pacientes para intemação encami nhados por outros hospitais de grande porte da Capital como a Santa Casa de São Paulo e Hospital das Clínicas e, finalmente, como retaguarda de intemação no atendimento de pacientes portadores de doenças infecto-con tagiosas, mais especificanente meningites e sarampo, encaminhados pelo Hospital Emílio filbas.

Cospital vinha ulitimamente apresentando grande ociosi dade, sendo que no levantamento realizado em abril de 1983, dos 350 lei tos colocados em operação apenas 80 - 100 leitos estavam ocupads, princi palmente devidio a pequena demanda de casos para intemarão e a ... pequena capacicade resolutiva, agravado principalmente pela inefícácia clos servi ços complementares de diagnóstico e terapêutica, com escassez de operado res de FK e pesscal habilitado de laboratório. 
H. I. ZONA NORTE

1 - CENTRO de CONVIVÊNCIA INFANTIL

2- HOSPITAL INFANTIL DA ZONA NORTE (Prédio central) BLOCO A-INTERNACÃO

BLOCO B-ADMINISTRACÃo

BLOCO C-INTERNAÇÃO

3 - ANATOMIA PATOLOGICA

4 - LAVANDERIA

5- OFICINAS

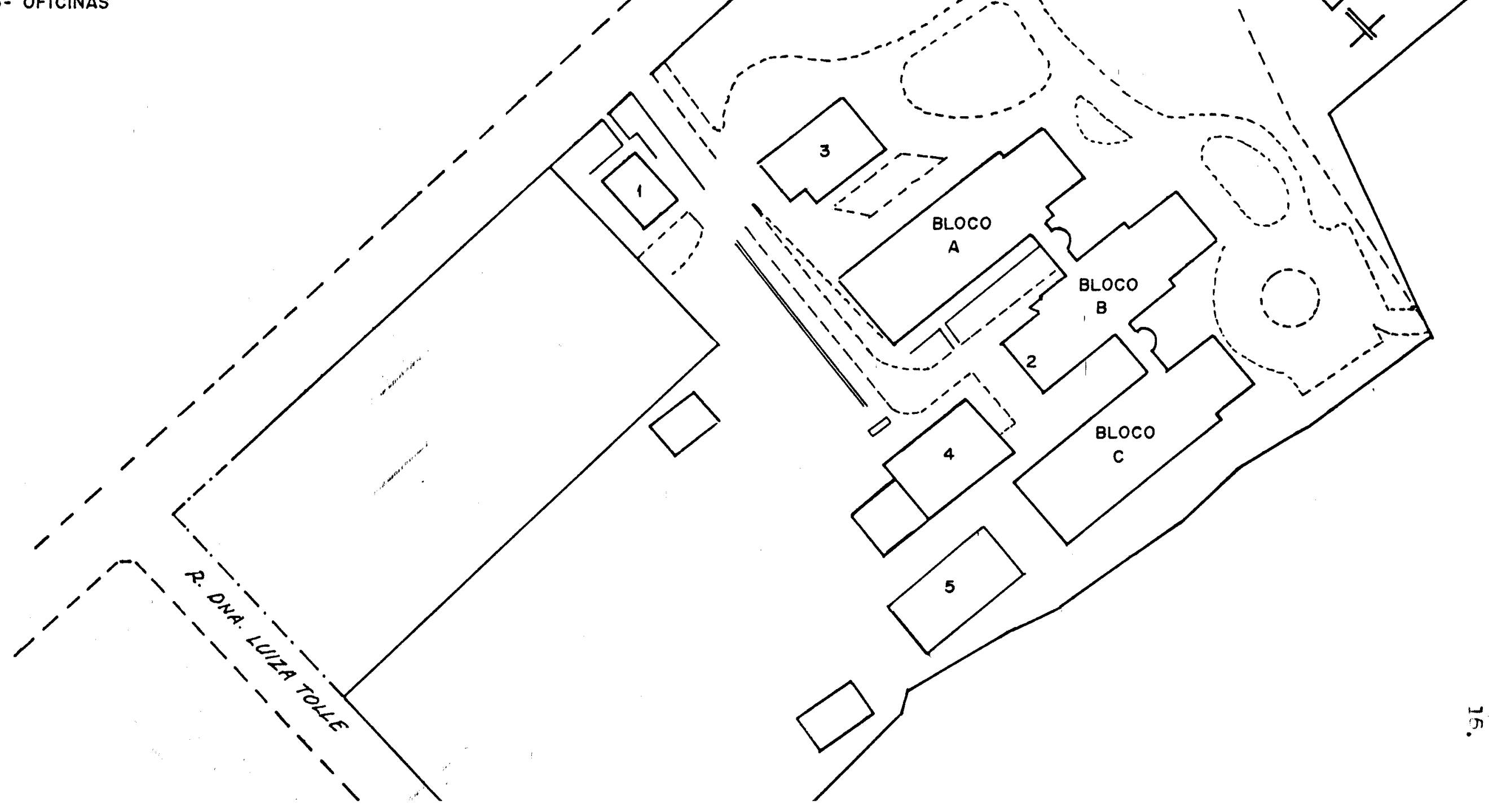


A Erande são paulo é a mais imnortante das regiñes metro nolitanas do brasil e é a maior repião metropolitana da Anérica latina. (mana I e Tabela I).

Esta regiãa possui ume superfície de $8.053 \mathrm{~km}^{2}$ e no últi mo censo de 1980 revelou possuir uma popularãa de 12.578.050 habịtantes , portanta $50,3 \%$ da população do Estado e $10,6 \%$ da populacão brasileira. (Tabela 2).

A população do lúunicípio de São Paulo compreende cerca de 67,5: da Grande São Paulo, ou seja cerca de 8,5 milhõés de habitentes e ocupa una área de $1.530 \mathrm{~km}^{2}$, correspondente a $19 \%$ da Grande São Paulo.

\subsection{O IUUICIPIO DE SAO PAULO}

- Municipio de São Faulo possuia em 1970, 5,9 milhões de habitantes, nassando pere 8,5 milhões em 1980, crescendo, portanto, em uma décàda, cerca de 2,6 milhões de habitantes. Apresenta uma densidade onpu lacional de 5.627 habitantes/rm². (Tabela 3 ).

Antigamente, a cidade de São Paulo apresentave-se diví dida em quatro zonas: Norte, SuI, Leste e Deste.

Atualmente é dividida em nove zonas con caracteristicas distintas: Centro Histórico, Centro Exnandido, Deste, Sul, Sudesto, Leste I Leste 2, Fural e Norte.

O hunicipio compreende 55 subdistritos e distritos de faz (Tabela 4 ).

A Coonderadoria de Análise de Dados da Secretaria de Eco nomia e Planejamento de São Paulo, em 1977, subdividiu os subdistritns do lunicípio de São Paulo em três áreas homorêneas, de acordo com alguns in dicadores econâmicos, sociais e denorréficos, tais comn renda familiar, densidade demorráfica, seneariento b́́sico, crescimenio ponuacional e mor 


\section{Mapa-1 \\ REGIÁO NETROPOLITANA DE SÃO PAULO}

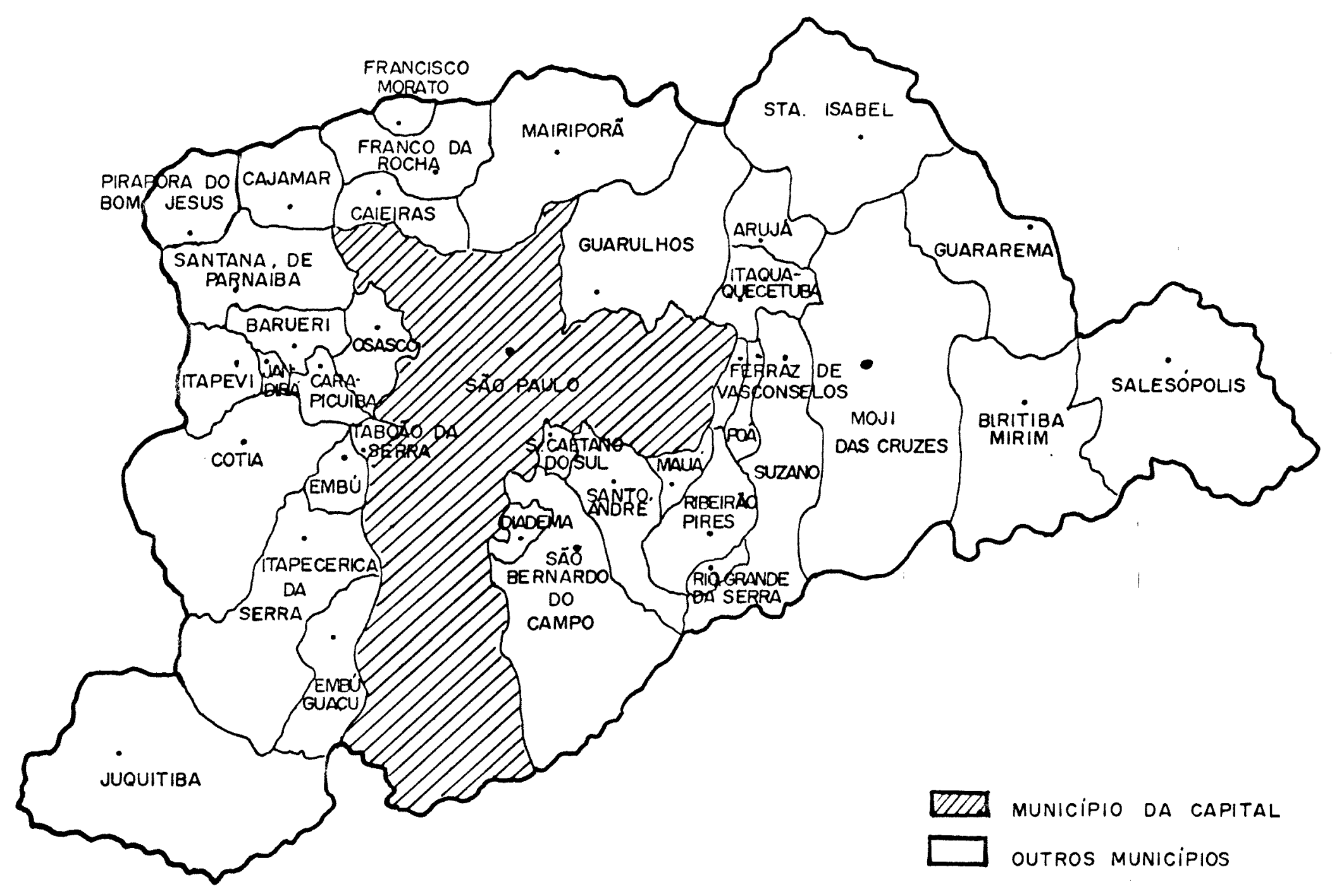


TABELA 1 - ESTADO DE SÃO PALILO

EVOLUCÃO DA DISTRIBUITAOO DA POPULACAO

\begin{tabular}{|c|c|c|c|}
\hline$A N O$ & $\begin{array}{l}\text { ESTADC DE SÃC PAIULO } \\
\text { (mil habitantes) }\end{array}$ & $\begin{array}{l}\text { ANSP - } \\
(\%)\end{array}$ & $\begin{array}{l}\text { DENATS } \\
\text { RESTRES }\end{array}$ \\
\hline 1940 & 7.180 & 21,8 & 78,2 \\
\hline 1950 & 9.134 & 30,0 & 70,0 \\
\hline 1960 & 12.874 & 32,0 & $E, 0$ \\
\hline 1970 & 17.772 & 45,3 & $5 c^{2}, ?$ \\
\hline $1930(1)$ & 25.023 & 50,3 & 42,7 \\
\hline
\end{tabular}

FOVTE: Censcs Demornáficos até 1970.

(1) Dados proliminares censo 90. 
TABela 2 - estado de săo paulo

AREAS, PGPULACẼES E DENSIDADE DEMOGFAFICA

1.980

\begin{tabular}{|c|c|c|c|c|c|}
\hline \multirow{2}{*}{ DTṢCAIMINAÇÃO } & \multicolumn{2}{|l|}{ AREA } & \multicolumn{2}{|c|}{ POPULAÇÃO } & \multirow{2}{*}{$\begin{array}{l}\text { DENSIDA- } \\
\text { DE } \\
\text { DEMOGRA- } \\
\text { FICA }\end{array}$} \\
\hline & $\begin{array}{l}\text { Extensão } \\
(K m 2)\end{array}$ & $\begin{array}{l}\text { Partici- } \\
\text { pação } \\
(\%) \quad-\end{array}$ & $\begin{array}{l}\text { Quantida } \\
\text { de } \\
\text { (mil ha- } \\
\text { bitantes) }\end{array}$ & $\begin{array}{l}\text { Partici } \\
\text { pação } \\
(\%)\end{array}$ & \\
\hline Grande São Paulo & 8.053 & 3,3 & 12.578 & 50,3 & $1.561,9$ \\
\hline Outras Regiões & 239.267 & 96,7 & 12.445 & 49,7 & 52,0 \\
\hline$E S T A D D$ & 247.320 & 100,0 & 25.023 & 100,0 & 101,2 \\
\hline
\end{tabular}

FONTE: Diagnóstico do Estado de São Paulo - SEF e dados preliminares Censo 80.

Enplasa - sumário 1980. 
TABELA 3 - GRAINDE SÃO PAULO

Area, Densidade Fopulacional e Taxa de Crescimento por Municipio de 1970 a 1980.

\begin{tabular}{|c|c|c|c|c|c|c|}
\hline MUNICÍPIOS DA FUMSP & $\begin{array}{c}\text { POPULAÇĀO } \\
1980\end{array}$ & $\begin{array}{l}\text { PEHCEN } \\
\text { TAGEN } \\
\text { PASP }\end{array}$ & $\begin{array}{l}\text { AFEA } \\
(K m 2)\end{array}$ & $\begin{array}{l}\text { DEINSIDADE } \\
\text { POPULACIO } \\
\text { NAL } 1980 \% \\
\text { Km2 }\end{array}$ & $\begin{array}{l}\text { POPULA- } \\
\text { ÇÃO } \\
1970\end{array}$ & $\begin{array}{l}\text { CPESCI- } \\
\text { MENTO } \\
1970 / 80 \\
(\%)\end{array}$ \\
\hline Arujá & 17.482 & 0,14 & 96 & 182 & 9.571 & 82,7 \\
\hline Barueri & 75.325 & 0,60 & 61 & 1.235 & 37.808 & 99,3 \\
\hline Biritiba-Mirim & 13.379 & 0,11 & 414 & 32 & 9.033 & 48,2 \\
\hline Caieiras & 25.066 & 0,19 & 104 & 241 & 15.563 & 61,1 \\
\hline Cajamar & 21.951 & 0,18 & 132 & 166 & 10.355 & 112,0 \\
\hline Carapicuiba & 185.250 & 1,47 & 36 & 5.146 & 54.873 & 337,6 \\
\hline Cotia & 62.569 & 0,50 & 354 & 177 & 30.924 & 102,4 \\
\hline Diaderna & 227.946 & 1,81 & 32 & 7.123 & 78.914 & 188,9 \\
\hline Embu & 95.538 & 0,75 & 68 & 1.405 & 18.148 & 425,5 \\
\hline Embu-Guaçu & 21.028 & 0,17 & 171 & 123 & 10.280 & 104,6 \\
\hline Ferraz de Vasconcel & & & & & & \\
\hline 105 & 55.107 & 0,44 & 25 & 2.204 & 25.134 & 119,3 \\
\hline Frencisco lloreto & 23.462 & 0,23 & 45 & 632 & 11.231 & 153,5 \\
\hline Franco da Rocha & 50.701 & 0,40 & 143 & 354 & 36.303 & 39,7 \\
\hline Guararema & 15.123 & 0,12 & 262 & 58 & 12.638 & 19,7 \\
\hline Euarulhos & 532.948 & 4,24 & 334 & 1.596 & 236.811 & 125,1 \\
\hline Itaquera da Serra & 60.441 & 0,48 & 328 & 184 & 25.314 & 138,8 \\
\hline Itapevi & 51.490 & 0,41 & 88 & 585 & 27.569 & 86,8 \\
\hline Itaquaquecetuba & 72.779 & 0,58 & 83 & 877 & 29.114 & 158,9 \\
\hline Jandira & 36.017 & 0,29 & 22 & 1.637 & 12.499 & 188,2 \\
\hline Juquitiba & 12.500 & 0,10 & 550 & 23 & 7.267 & 72,1 \\
\hline iairiporã & 27.495 & 0,22 & 307 & 90 & 19.584 & 40,4 \\
\hline Viauá & 205.817 & 1,63 & 67 & 3.072 & 101.700 & 102,4 \\
\hline Moji das Cruzes & 198.082 & 1,57 & 731 & 271 & 138.751 & 42,8 \\
\hline Gsasco & 472.535 & 3,76 & 68 & 6.949 & 283.073 & 67,0 \\
\hline Pirapora do fom & & & & & & \\
\hline Josus & 4.815 & 0,03 & 99 & 49 & 3.709 & 29,9 \\
\hline Póá & 52.795 & 0,42 & 35 & 1.508 & 32.373 & 63,1 \\
\hline Fibeirão Pires & 56.263 & 0,45 & 109 & 516 & 29.048 & 93,7 \\
\hline Pio Grande da Serra & 20.089 & 0,16 & 33 & 609 & 8.397 & 139,3 \\
\hline Salesópolis & 10.649 & 0,08 & 418 & 25 & 9.557 & 11,5 \\
\hline Santa Izabel & 28.997 & 0,23 & 361 & 80 & 17.161 & 69,0 \\
\hline Santena do Farnaiba & 10.070 & 0,08 & 179 & 56 & 5.390 & 36,9 \\
\hline Santo André & 552.751 & 4,40 & 180 & 3.071 & 418.826 & 32,0 \\
\hline S.Eemarto do Campo & 425.122 & 3,38 & 411 & 1.034 & 201.662 & 110,8 \\
\hline São Paulo & 8.490 .768 & 67,50 & 1.509 & 5.627 & 5.924 .615 & 43,4 \\
\hline Suzano & 101.067 & 0,80 & 167 & 605 & 55.460 & 82,3 \\
\hline Tabcão da Serra & 96.732 & 0,77 & 20 & 4.837 & 40.945 & 136,3 \\
\hline S. Caetano do Sul & 162.901 & 1,30 & 11 & 14.809 & 150.130 & 8,5 \\
\hline$T D T A L$ & 12.578 .050 & 100,00 & 8.053 & 1.562 & 8.139 .730 & 54,6 \\
\hline
\end{tabular}

FONTES: População 1980 - Dados Preliminares - Censo IBGE 
TABELA 4 - MUNICIPIO DE SÃO PAULO POPULACYAO, AREA, TAXA DE CFESCIMENTO E DENSIDADE POR DISTRITO E SUBDISTAITO DE PAZ DE 1970 a 1980

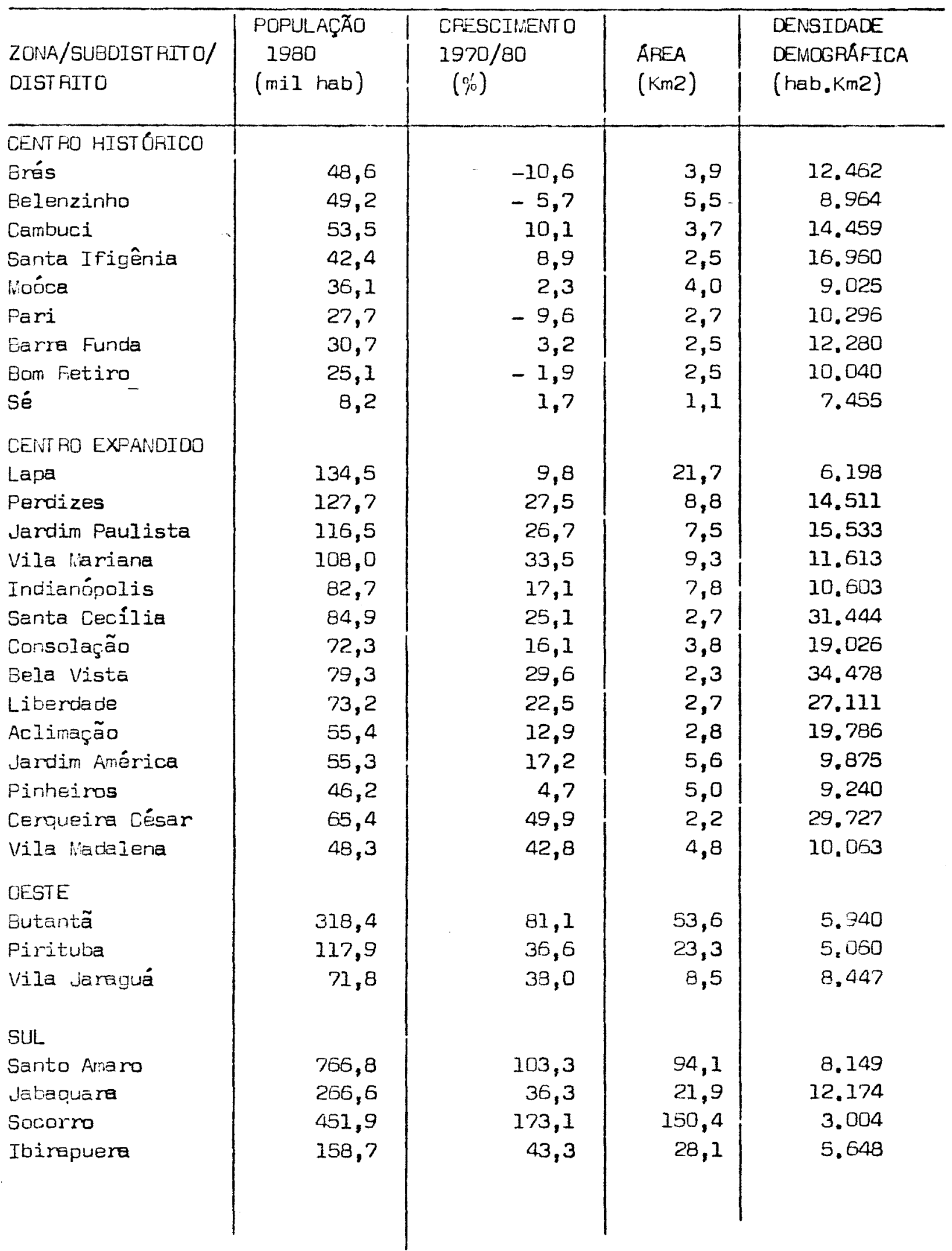




\begin{tabular}{|c|c|c|c|c|}
\hline $\begin{array}{l}\text { ZONA/SUBDISTRITO/ } \\
\text { DISTRITO }\end{array}$ & $\begin{array}{l}\text { POPULAÇAO } \\
1980 \\
\text { (mil hab) }\end{array}$ & $\begin{array}{l}\text { CRESCIMENTO } \\
1970 / 80 \\
(\%)\end{array}$ & $\begin{array}{l}\text { AFEA } \\
(\mathrm{Km} 2)\end{array}$ & $\begin{array}{l}\text { DENSIDADE } \\
\text { DENOGFAFICA } \\
\text { (hab. Km2) }\end{array}$ \\
\hline \multicolumn{5}{|l|}{ SUDESTE } \\
\hline Vila frudente & 496,5 & 38,2 & 31,6 & 15.712 \\
\hline Saúde & 289,0 & 23,2 & 21,4 & 13.505 \\
\hline Ipiranga & 179,3 & 4,6 & 16,3 & 39.978 \\
\hline Alto da Moóca & 136,5 & $-0,4$ & 9,8 & 13.929 \\
\hline \multicolumn{5}{|l|}{ LESTE 1} \\
\hline Tatuapé & 280,0 & 10,1 & 25,7 & 10.891 \\
\hline Ermelino Natarazzo & 241,6 & 58,7 & 24,9 & 9.703 \\
\hline Vila Vatilde & 239,6 & 58,5 & 21,1 & 11.355 \\
\hline Penha de França & 142,5 & 3,4 & 11,6 & 12.284 \\
\hline Vila Formosa & 120,3 & 24,9 & 8,7 & 13.828 \\
\hline Cangaíba & 75,3 & 25,8 & 9,1 & 8.275 \\
\hline \multicolumn{5}{|l|}{ LESTE 2} \\
\hline são liiguel Paulista & 445,7 & 212,4 & 38,8 & 11.487 \\
\hline Itaquera & 414,6 & 119,2 & 57,7 & 7.185 \\
\hline Gusianazes & 160,4 & 100,8 & 67,7 & 2.222 \\
\hline \multicolumn{5}{|l|}{ NORTE } \\
\hline Tucuruvi & 462,8 & 28,8 & 88,6 & 5.223 \\
\hline Santana & 247,0 & 38,2 & 33,9 & 8.083 \\
\hline Nossa Senhora do $0^{\prime}$ & 174,0 & 23,3 & 11,8 & 14.746 \\
\hline Vila :aria & 131,0 & 12,6 & 11,1 & 11.802 \\
\hline Brasilândia & 176,3 & 76,7 & 19,4 & 9.088 \\
\hline Casa Verde & 110,6 & 11,8 & 7,1 & 15.577 \\
\hline Vila Guilherme & 77,0 & 4,0 & 7,2 & 10.694 \\
\hline Limão & 86,1 & 23,1 & 6,1 & 14.114 \\
\hline V. Nova Cacheirinha & 37,4 & 21,0 & 2,5 & 14.960 \\
\hline \multicolumn{5}{|l|}{ PUSAL } \\
\hline Perus & 48,4 & 74,4 & 56,7 & 853 \\
\hline laraguá & 51,1 & 144,0 & 35,8 & 1.427 \\
\hline Parelheiros & 27,3 & 120,6 & 389,2 & 70 \\
\hline I.UUNICIPIO DE S.PAULO & $8.490,7$ & 43,3 & $1.509,0$ & 5.627 \\
\hline
\end{tabular}

FONTE: SIPLAN - EMPLASA - Sumário de Dados - 1979 e Dados Preliminares, Censo 80. 
taliciede proporcional, entre outros. ( i.epa 2 ).

Essas 3 éreas foram assim divididas:

- Central

- Intemediária

- Feriférica.

A área ceridrel compreende os 14 distritos de melhor quali dade de vida. Vivem nessa área a ponuląão de rencia mais alta. Encon tie-se na área centrel, una alta densidade demográfica, níveis de saúde satisfatório e buas condições de edificações para uso residencial.

A área intermediéria é constituida dos distritos nais ariti gos e centrais da cidade de São Paulo.

A área periférica é a áres que essume imoortância no pre sente estudio, já que o Hospital Infantil da Zora Worte e farque Hospita lar do lendaqui estẽo é locelizados, en un dos seus Distritos, o de Tucu ruvi. Caracteriza-se por apresentar os hiveis baixos de renda e de saú de dis Éreas descritas, elevadas taxas de crescimento populacional, in Pre-estruture tésica em condicões precérias, tudo isso traduzindo condi ções inadequadas de vida.

O crescimento populacional na érea periférica teve um au riento de $2, I$ milhões de habitentes na última década. Este crescinerico E extraordinériamente grende em comparacão com os 244 mil habitantes na intermediária a 179,9 mil ná área central. (Tabela 5 ).

Os Hospitais, apesar de se Iocalizarem no Distrito de Tü curuvi, cuerdam estreita relagão com es Cistritos de vila laria e Viessa Eenhora do e' devido as suas lucalizacões, fecilidedes de deslocamento, acessibilidacle e nesmo semelhanca populacional e nivel econômico social.

Fara 1983, a populagão Estirada do Distrito Sanitário de Tucuruvi é de 775.512 habitantes, enquanto que a do Distrito Sanitário 


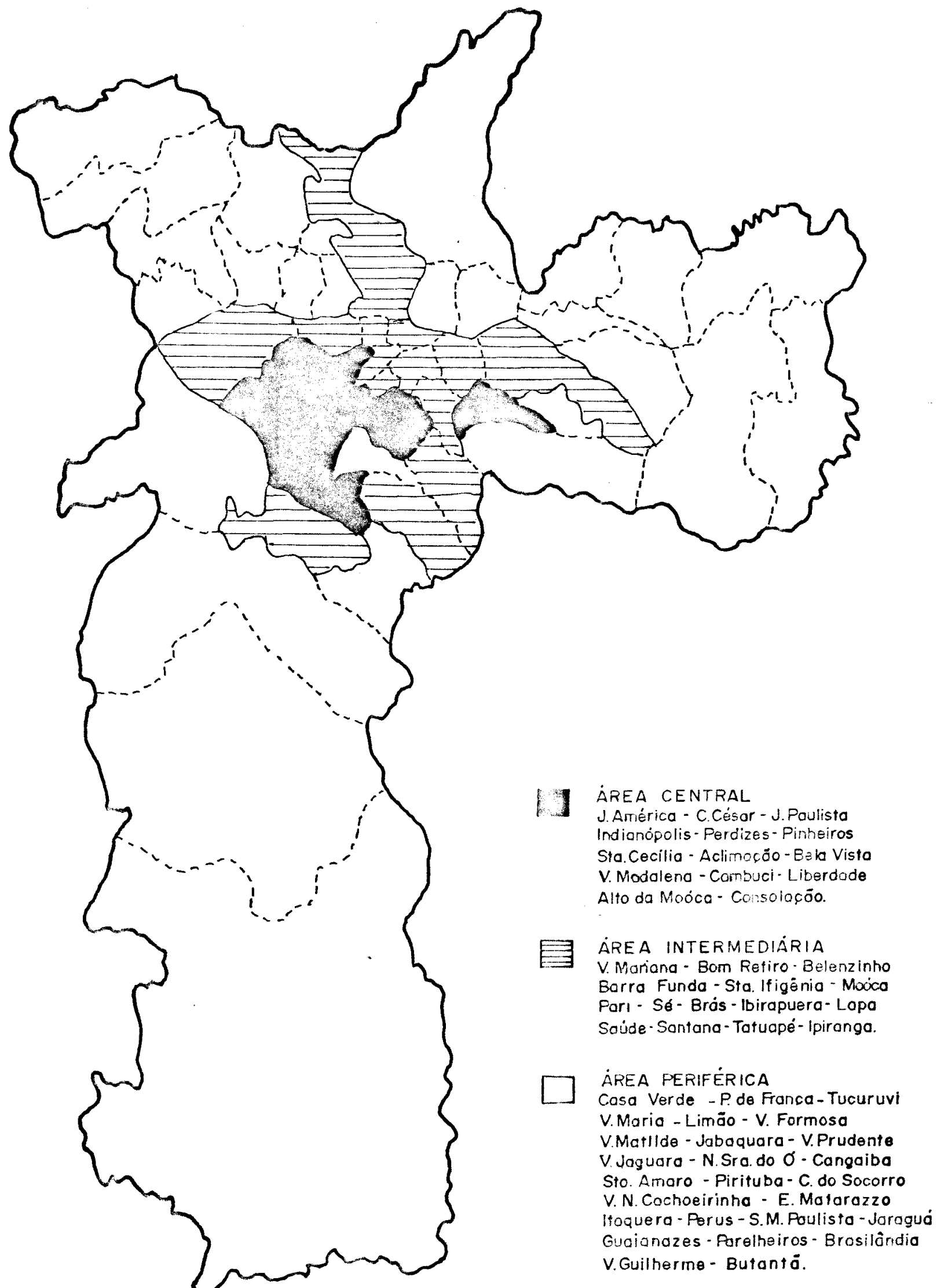


TAAELA 5 - Crescimentr ponulacional nas áreas central, intemediéria e periférica do lunicínio de São Paulo nos anos 1970/80.

\begin{tabular}{|c|c|c|c|c|}
\hline $\begin{array}{l}\text { POPULACẼO } \\
\text { AREA }\end{array}$ & $\begin{array}{l}\text { Ne de } \\
\text { hahitantes/70 }\end{array}$ & $\begin{array}{l}\text { No de } \\
\text { habitantes/80 }\end{array}$ & $\begin{array}{l}\text { Diferenca } \\
70 / 80\end{array}$ & $\begin{array}{l}\text { ¿de } \\
\text { crescirento }\end{array}$ \\
\hline Centrel & 917.277 & 1.097 .182 & 179.905 & 19,61 \\
\hline Intermediária & 1.447 .696 & 1.691 .718 & 244.022 & 16,85 \\
\hline Feriférica & 3.559 .642 & 5.701 .858 & 2.142 .226 & 60,18 \\
\hline$T O T A L$ & 5.924 .615 & 8.490 .768 & 2.555 .153 & 43,31 \\
\hline
\end{tabular}

FORTE: IBGE 
Vessa Sinhore do $0^{\prime}$ é de 618.302 hatitantes, e o Distrito Sanitário Vila lierie, o menor, com 208.527 habitantes, tatalizando as 3 áreas, uma popu Iação de 1.602.341 habitantes. (Tabela 6) ).

\section{2 - DISTFTTCS DE TUCURUVI, VILA VIARTA E NOSSA SENHOFA DO O'.}

Com o estudo nue dividiu o l.unicípio de São paulo, segun do área Centrel, Intemediéria e Perif́érica em 1977, realizado pela Em presa lietropolitena de Flanejamento ( EI:PLASA F, através da Pesouisa öri gêm Destino ( O.D.), foi consideredo a raixa de renda familiar de até 5 sálérios minimos mensais, como Iimite de subsistência e ataixo de 5 selé rios, a família seria consiciereda carente. observou-se que grancie per cela da populacão carente incluie-se na faixe de 0 a 3 selárins mínimos. ( Tabela 7 ).

A área periférica do liunicípio de São Paulo, onde se in cluem os Distritos de Tucuruvi, llossa senhora do e vila liaria, tem $55,7 \%$ de sua ponularão recebendio nenos de 5 salárícs minzmos. (Viapa 3 ).

\section{HAETTACÃO}

A questão habitacional na cidade de São Paulo tomou-se , nos últinos 20 anos, um dos problemes sociais da maior importância, devi do principalmente ao próprio crescimento vegetativo, aliado a um fluxo migratório de checada à Capital Paulista, riãa acomanhados oor uma pre visẽo governamentel. Agravante ainda, foram as recentes medidas finan ceires govemamentais na área habitacional, once milheres de Chefes de família estão impediós de manterem a casa própria.

Habitualmente, a população migranie se localiza e se fixa nos limites periféricos da ciciace, onde as moradias são mais baratas, on de as servicos públicus são menos prestados $e$ as conciições de sanea mento bésicos são as piores, constituindo aglomerações desorganizadas e habita-ões precáries, sen serviros tésicos cono rede de água e esgo tos, coleta de lixo, energia elétrica, escolas públicas, transportes 
TABELA 6 - DADOS POPULACIONATS: POPUL.AC,XO SEGUNDO CENSO DE 1970,1980 e 1983 E A TAXA DE CRESCIMENTO DO PERIODO DOS D.S. DO ORS - 1-2.

\begin{tabular}{|c|c|c|c|c|}
\hline $\begin{array}{l}\text { POPULA,AOA } \\
\text { DISTRITO } \\
\text { SANTTARIO }\end{array}$ & $\begin{array}{l}\text { POPLILAC } X_{0} \\
1.970 \\
\text { Censo }\end{array}$ & $\begin{array}{l}\text { РОРИルACAO } \\
1.980 \\
\text { Censo }\end{array}$ & $\begin{array}{l}\text { TAXA DF } \\
\text { CAESCIMENTO }\end{array}$ & $\begin{array}{l}\text { POPULAC,.XO } \\
1.983\end{array}$ \\
\hline D.S. CAIEIRAS & 92.311 & 153.675 & 66,5 & 176.077 \\
\hline D.S. LAPA & 307.062 & 423.727 & 38,0 & 455.574 \\
\hline D.S. N.SENHDRA DO O' & 437.273 & 584.475 & 33,6 & 618.302 \\
\hline D.S. TUCUPUVT & 553.272 & 736.885 & 33,1 & 775.512 \\
\hline D.5. VII_A MARIA & 188.828 & 207.960 & 10,1 & 208.527 \\
\hline DRS - 1-2 & 1.578 .740 & 2.106 .722 & 33,4 & 2.233 .992 \\
\hline
\end{tabular}




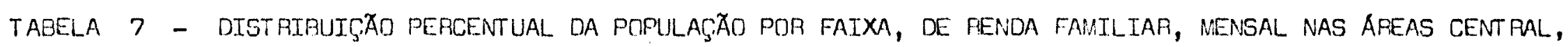
INTERMEDIARIA, PERTFÉRICA E MUNICIPJO DE SAO PAULO

\subsection{3}

\begin{tabular}{|c|c|c|c|c|c|}
\hline INTERMEDIARIA & 16,71 & 17,92 & 36,27 & 29,10 & 100,00 \\
\hline PERIFERICA & 26,17 & 28,92 & 35,33 & 9,58 & 100,00 \\
\hline
\end{tabular}

FONTE: EST IMAT IVA COGEP

Seçäo de Estatística - SHS. Gabinete - 24/06/83 
PORCENTAGEM DE POPULACAO COM MENOS DE CINCO SALARIOS MINIMOS DE RENDA FAMILIAR POR AREAS HOMOGENEAS DO MUNICIPIO DE SAO PAULO.

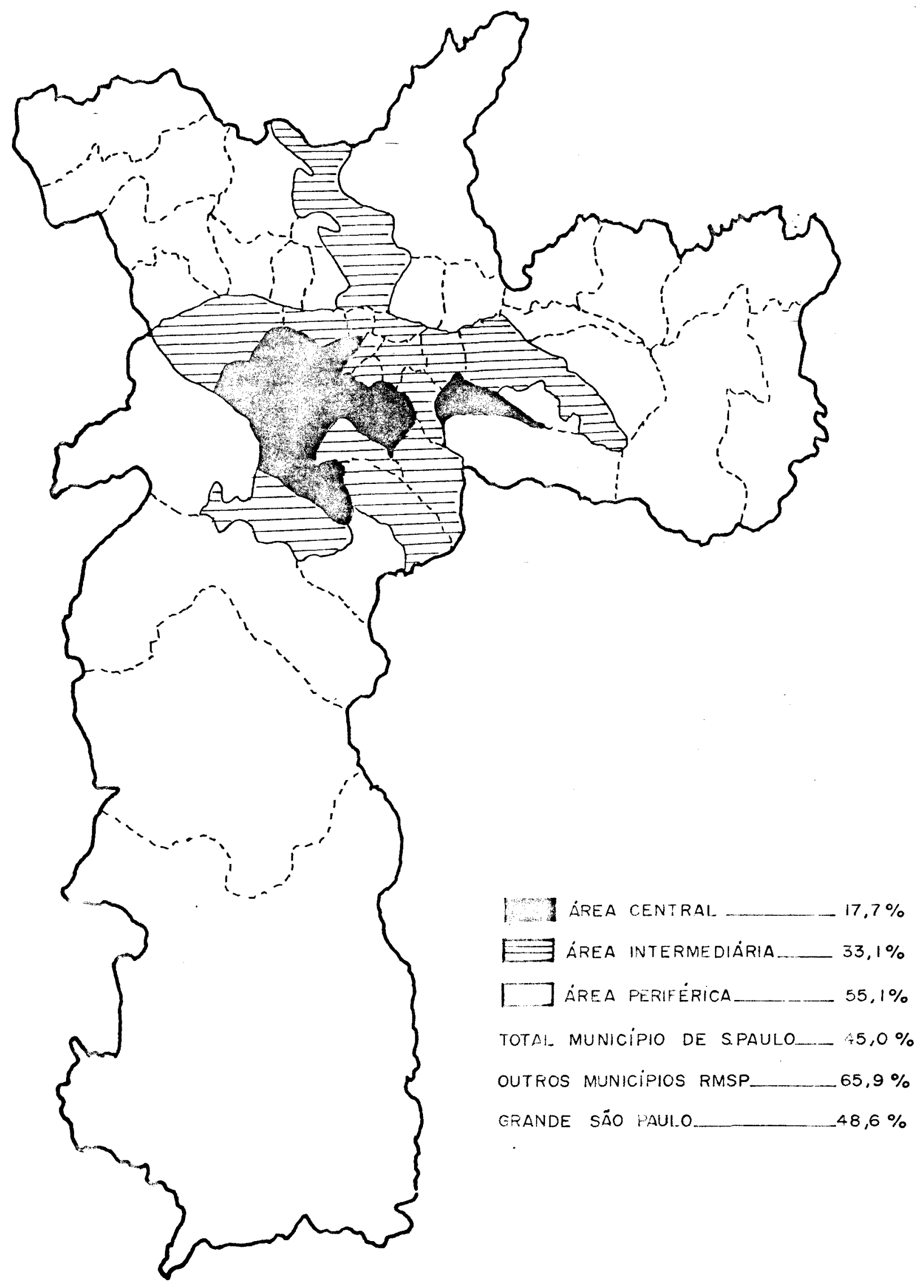


A populacão de baixa renda dispõe em São Paulo, Canital, 4 alter ráives re moradia: feveles, corticos, conjuntos habitacionais e casa de periferia.

Conforme Ievantanento da Fundagẽo Instituto Erasileiro de Geogra fia e Estatistice, num estudio nré-censitório de 1980, (Tabela 6), existem no lunicínio de Gão Feulo cerca de 27.702 barrecos, agrupados en 681 fá velas, com 5, 15 pesscas por donícilio e a ravele sendo deíinida como um núcleo de rais de 50 sarracos.

Cedos mais recentes da Secretaria da femília e do Eem Estar So cial (ftess), de acosto de 1963, revelam, para o iunicípio de São Paulo, a presenca de 1.086 favelas, sendo que o Distrito de Tucuruvi possui 35 , bossa Senhora do O' 165, a Vila Varia. 97 faveles, perfezendo em habitan tes para o iunicípio de São Paulo 414.57?, sendo destes 45.874 na Fregue sia do 0', E.074 no Tucumvi e 34.120 en vila liaria.

Outra alterrative habitacionel são cs cortiços. Caracterizam-se os cortịos como sencio cesa de vários cômudos ou ç̂modos construidos no mesmo terreno, onde cada familia ocuba un cubículo de pequeras dimensões ou perte desie e utiliza, coletivamente, es instalações sanitárias.

Mum relatório do Plano de Eoverno da Prefeitura, elaborado 1977, existiam, no Município de São Psulo, aproximadamente 1,9 milhões de pesscas habitencio corticos.

D nimero atuel estiriado de cortiros no lunicinio de Gão Paulo é de 125.939, sendo cue destes, $10.45 e$ se encontram no Distrito de lossa Senhore do or, 7.323 no de Tucumvi e 5.975 no de vite lamia.

C total estinado da popularão habitando cortínos, em São Paula, é de 3.277.571, sendo losa Senhora do O' com 280.094, Tucuruvi com 196.680 e Vila leria con 185.680 pesscas.

Entre a pooulạ̃a que habita faveles e cortiços nas 3 áreas em foco, temos um total nopulacional estirnado em 759.122 habitantes.

As duas outras alternativas dizem respeito a casa de periferia ou casa de subúrbio e aos Conjuntos Habitacionais, ambos com menor par ticipação. 
TABEla 8 - Número de Favelas, Barracos, Favelados, Densidade e Participação dos Favelados na população por Areas Central, Intermediária a Periférica do Município de São Paulo - 1.980

\begin{tabular}{|c|c|c|c|c|c|}
\hline AFEAS & $\begin{array}{l}\text { No DE } \\
\text { FAVEL_AS }\end{array}$ & $\begin{array}{l}\text { NO DE } \\
\text { BARRACOS }\end{array}$ & $\begin{array}{l}\text { No DE } \\
\text { FAVELADOS (I) }\end{array}$ & $\begin{array}{l}\text { DENSTDADE } \\
\text { (FAVELADDS } / \mathrm{km} 2 \text { ) }\end{array}$ & $\begin{array}{l}\text { PARTTCTPACAO } \\
\text { (FAVEL_ADOS / POP) }\end{array}$ \\
\hline CENT PAL & 20 & 612 & $3.15 ?$ & 45,4 & 0,29 \\
\hline INTERMEDIARIA & .22 .4 & 9.885 & 50.878 & 252,2 & 3,00 \\
\hline PEFIFFRICA & 537 & 77.205 & 397.605 & 315,9 & 6,97 \\
\hline TOTAL & 681 & 87.702 & 451.665 & 299,3 & 5,32 \\
\hline
\end{tabular}

FONTE: FIBGE - SP, levantamento pré-censitário, 1980

(1) Admite-se a densidade de 5,15 pessoas por barraco 
33.

- - ALGUIS IIDICADORES DE SAÚdE WA CIDADE DE SR̃C PAULO E FEGIAOC NOFTE, DISTFIT OSOE TUCUFUVI, VILA LIFFIA E FFEGUESIA DO D'

\section{G.I - WETTALIDADE GEFAL}

A mortalidade ceral no Lunicínio de são Paulo decresceu nos últimos anos, devendo-se ressaltar no entanto, ao se analiser os da dos, que a população naulistana apresenta $43 \%$ de sua população com idade menor que 20 anos e E3!: menores de 45 anos (Tabela 9 e Gráfico I). 6.2 - MOETALIDADE PFOPOFCIONAL EN UENOFES DE I ANO DE IDADE

A mortalidade proporcional em mencres de 1 ano nostra o de so des óbitos nesta feixa etária, en relação ao total de óbitos e, no liu nicípio de São Paulo, esta porcentagem clecresceu de 27,6 em 1971 para 22,00 em 1921. (Tebela 10).

Dbservamus ainda cue re resião periférica, onde se encontram as áreas cstudades, o m smo comportanento se faz presente, ponén com valo res elevados aes encontrados nas regiões intemediária e central, e en ou tras regiões consideradas desenvolvidas no resto do mundo.

\section{3 - FLZAEO DE I.OFTALIDADE PFGPCFCIOHAL FAFA IAATOFES DE 50 AMOS.}

O indicadorde Svaroop e Uemura, que é a razão de mortalidade proporcional para maiores de 50 anos, apresentia una tendência à melhora (Ta bela 11 ).

Apesar do aumento progressivo observado de 1971 a 1981,os va lores encontrados, para o hunicíoio de São Paula, estão muttodáixo do de sejével.

\section{$5.4-$ MUTALIDADE IMEAIIIL}

E considerado como um dos melhores incicadores des condifrón de saúde de una população.

Ao se arialisar os dados apresentados (Tabela 12), notamos uma diminuição dos valores encontrados, especialmente nó áreas central e inter mediéria, onde desde 1977, o indicador está abaixo de 50 óbitos por mil nas 
TABELA 9 - COEFICIENTE DE MORTALIDADE GERAL NAS AREAS CENTRAL, INTERINEDIARIA PERIFERICA E MUNICIPIO DE SÃO PAULO

$$
1971-81
$$

\begin{tabular}{|c|c|c|c|c|}
\hline \multirow{2}{*}{ ANO } & \multicolumn{3}{|c|}{ COEFICIENTE DE MORT ALIDADE GEPAL } & \multirow[b]{2}{*}{$\begin{array}{l}\text { MUNICIPIO } \\
\text { DE SÃO PAULO }\end{array}$} \\
\hline & CENTRAL & IIVTERMEDIARIA & PERIFERICA & \\
\hline 1971 & 8,27 & 8,86 & 7,40 & $8,27^{-}$ \\
\hline 1972 & 7,93 & 8,66 & 7,73 & 7,98 \\
\hline 1973 & 8,50 & 8,83 & 7,98 & 8,26 \\
\hline 1974 & 7,60 & 8,46 & 7,84 & 7,95 \\
\hline 1975 & 7,29 & 8,16 & 7,39 & 7,56 \\
\hline 1976 & 7,24 & 7,91 & 7,21 & 7,37 \\
\hline 1977 & 6,95 & 7,06 & 6,35 & 6,59 \\
\hline 1978 & 7,05 & 7,16 & 6,61 & 6,79 \\
\hline 1979 & 7,25 & 7,66 & 6,37 & 6,75 \\
\hline 1980 & 6,70 & 7,69 & 5,98 & 6,41 \\
\hline 1981 & 6,56 & 7,47 & 5,87 & 6,55 \\
\hline
\end{tabular}

FONTE: SEADE

* por 1000 habitantes

Seção de Estatística - SHS - Gabinete - 24/06/83 
Gráfico 1

PIRÁMIDE POPULACIONAL DA REGIĀO METROPOLITANA DE SAOO PAULO - 1979

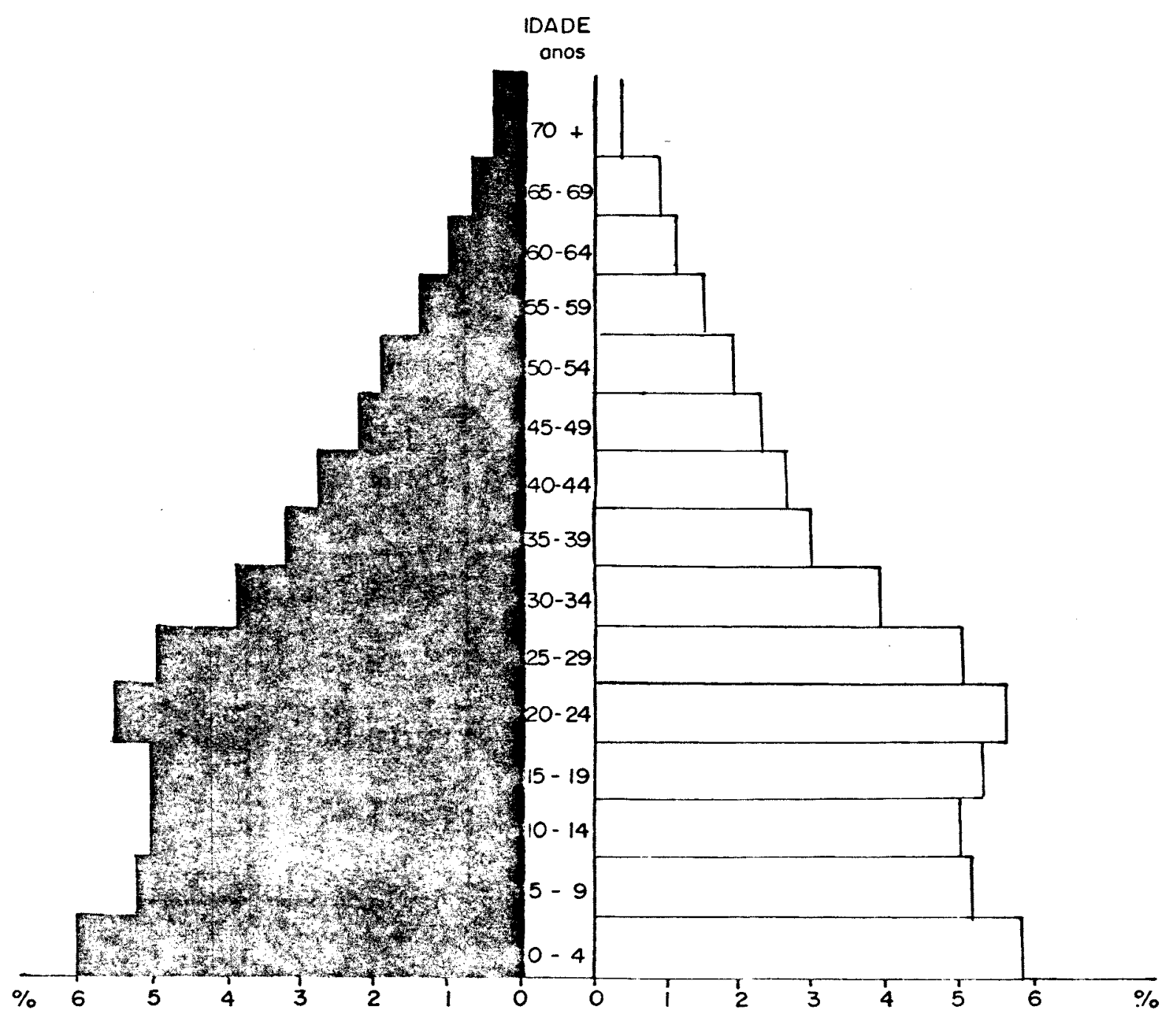

HOMENS

$\int$ MULHERES

FONTE: PNAD 1979 
tABELA 10 - MOATALIDAdE PROPORCIONAL DE MENORES dE I ANO NAS ÁpEAS CENTRAL, INTERMEDIÁRIA, PERIFÉRICA E MUNICIPIO DE SÃo PAULO

$$
1.971-81
$$

\begin{tabular}{|c|c|c|c|c|}
\hline \multirow{2}{*}{ ANO } & \multicolumn{4}{|c|}{ MORTALIDADE PROPORCIONAL DE MENORES DE I ANO } \\
\hline & CENT FAL & INTERIMEDIARIA & PERIFERICA & $\begin{array}{l}\text { MUNICIPIO DE } \\
\text { SAOO PAULO }\end{array}$ \\
\hline 1971 & 15,33 & 20,05 & 34,60 & 27,60 \\
\hline 1972 & 14,56 & 18,96 & 34,71 & 24,67 \\
\hline 1973 & 14,07 & 19,17 & 33,68 & 27,10 \\
\hline 1974 & 13,94 & 18,50 & 31,71 & 26,03 \\
\hline 1975 & 16,07 & 19,17 & 34,83 & 28,44 \\
\hline 1976 & 15,18 & 17,87 & 33,80 & 27,33 \\
\hline 1977 & 14,17 & 17,83 & 31,76 & 25,97 \\
\hline 1978. & 12,72 & 16,36 & 31,79 & 25,61 \\
\hline 1979 & 11,87 & 15,14 & 29,76 & 23,84 \\
\hline 1980 & 10,84 & 13,86 & 26,07 & 21,08 \\
\hline 1981 & 11,10 & 14,76 & 27,04 & 22,00 \\
\hline
\end{tabular}

FONTE: SEADE

* por 100 óbitos gerais

Seção de Estatística - SHS. Gabinete - 24/06/83 
TABELA 11 - RAZÃO DE MORTALIDADE PROPOACIONAL (SWAROOP E UEMURA) NAS ÁREAS CENT RAL, INTERMEdIÅRIA, PERIFÉRICA E MUNICÍPIO dE SĂO PAULO

$$
\text { 1971, 1976, } 1979 \text { e } 1981
$$

\begin{tabular}{|c|c|c|c|c|}
\hline \multirow{2}{*}{ AREA } & \multicolumn{4}{|c|}{ RAZAO DE MORTALIDADE PROPORCIONAL 50 a MAIS } \\
\hline & 1971 & 1976 & 1979 & 1981 \\
\hline CENT FAL & 62,24 & 64,93 & 69,95 & 72,27 \\
\hline INTEFH.IEDIAFIA & 55,90 & 60,79 & 64,32 & 65,25 \\
\hline PERIFERICA & 37,90 & 39,91 & 43,36 & 45,58 \\
\hline $\begin{array}{l}\text { MUNICIPIO DE } \\
\text { SÃO PAULO }\end{array}$ & 46,62 & 48,31 & 51,99 & 53,34 \\
\hline
\end{tabular}

FONTE: SEADE

Seção de Estatística - SHS. Gabinete - 24/06/83 
TABELA 12 - COEFICIEIJTE DE MORTALIDADE INFANTIL NAS AREAS CENTRAL, INTERME DIARIA, PEAIFERICA E MUINICIPIO DE SÃO PAULO

$$
1.971-81
$$

\begin{tabular}{|c|c|c|c|c|}
\hline \multirow{2}{*}{ ANO } & \multicolumn{4}{|c|}{ COEFICIENTE DE MORTALIDADE INFANT IL } \\
\hline & CENT RAL & INTERMEDIARIA & PERIFERICA & $\begin{array}{l}\text { MUNICIPIO DE } \\
\text { SÃO PAULO }\end{array}$ \\
\hline 1971 & 62,26 & 67,11 & 96,90 & 85,38 \\
\hline 1972 & 58,39 & 61,63 & 98,78 & 85,66 \\
\hline 1973 & 60,40 & 65,87 & 99,50 & 87,20 \\
\hline 1974 & 51,56 & 60,52 & 94,38 & 78,02 \\
\hline 1975 & 55,72 & 59,03 & 89,91 & 79,28 \\
\hline 1976 & 53,03 & 52,63 & 85,34 & 74,88 \\
\hline 1977 & 49,19 & 46,53 & 75,80 & 66,63 \\
\hline 1978 & 48,35 & 44,45 & 80,39 & 69,26 \\
\hline 1979 & 42,74 & 44,16 & 61,86 & 56,97 \\
\hline 1980 & 31,87 & 42,47 & 52,12 & 48,87 \\
\hline 1981 & 37,57 & 45,71 & 52,83 & 50,01 \\
\hline
\end{tabular}

FONTE: SEADE

* por 1000 nescidos vivos

Seção de Estatística - SHS. Gabinete - 24/06/83 
cidos vivos.

Os valores encontrados para a região periférica de São Pau Io suplantan sempre os encontrados para as regiões intermediária e cen tral.

Ao se dividir a mortalidade infantil em seus 2 componentes (Tabela 13 ), neonatal e infantil tardio, e os analisarmos de 1971 a 1981 comparativamente nas regiões centrel, intermediária e periférica, no tamos que somente na área central e intermediária o componente neonatal predomina soure a mortalidade infantil tardia. Por outro lado, o que se observa é que a mortalidade infantil tardia é maior que a neonatal na região periférica, demonstrando que outros fatores ligados ao meio, como sancamento, habitação, condições nutricionais e doenças infantis preveni cias por vacinação predominan em relação aos fatores ligados ao parto e ao períado neonatal.

\section{5 - PFIMCIPAIS CAUSAS DE GEITO}

A análise dos indicadores de saúde adquire uma maior impor tância, quancio acompanhada de estudo sôbre as principais causas de óbito nas diferentes faixas etárias.

Nas tabelas 14, 15 e 16 temos as principais causas de óbi tos para menores de 1 ano, em 1981, para as áreas central, Intermediária e Feriférica do llunicípio de São Paulo.

Observe-se que, na érea periférica, as 3 principais causas são as pneumonias ( $21,42 \%$ ), as lesões ao nescer, partos distócicos, outras ấeç̃ôes anóxicas e hipóxicas perinatais $(21,36 \%) \mathrm{e}$, as enteri tes e outras doerfas diarréicas ( $17,45 \%$ ).

iva área intemediária, as causes, em ordem de importância, são as lesões ao rascer, partos distócicos e outras afecções e hipóxicas/ 
TABELA 13 - MORTALIDAOE NEO NATAL E INFANTIL TARDIA - NAS DIFERENTES AFEAS DO MUNICIPIO DE SÃO PAULO DE 1.971 a 1.981

\begin{tabular}{|c|c|c|c|c|c|c|c|c|}
\hline \multirow[b]{2}{*}{ ANO } & \multicolumn{2}{|c|}{ CENTRAL } & \multicolumn{2}{|c|}{ INTERMEDTARIA } & \multicolumn{2}{|c|}{ PERIFERICA } & \multicolumn{2}{|c|}{ MUNICÍPIO DE SÃO PAULO } \\
\hline & $\begin{array}{l}\text { NEO } \\
\text { NATAL }\end{array}$ & $\begin{array}{l}\text { INFANTIL } \\
\text { TARDIA }\end{array}$ & $\begin{array}{l}\text { NEO } \\
\text { NATAL }\end{array}$ & $\begin{array}{l}\text { INFANT IL } \\
\text { TARDIA }\end{array}$ & $\begin{array}{l}\text { NEO } \\
\text { NAT AL }\end{array}$ & $\begin{array}{l}\text { INFANT IL } \\
\text { TARDIA }\end{array}$ & $\begin{array}{l}\text { NEO } \\
\text { NATAL }\end{array}$ & $\begin{array}{l}\text { INFANT IL } \\
\text { TARDIA }\end{array}$ \\
\hline 1971 & 32,39 & 29,83 & 37,07 & 30,04 & 42,61 & 54,29 & 40,01 & 45,37 \\
\hline 1972 & 31,66 & 26,73 & 33,01 & 28,62 & 43,83 & 55,95 & 39,77 & 45,89 \\
\hline 1973 & 30,63 & 29,77 & 35,33 & 30,54 & 43,61 & 55,89 & 40,20 & 47,00 \\
\hline 1974 & 28,37 & 23,19 & 32,31 & 28,21 & 36,68 & 57,70 & 34,77 & 43,25 \\
\hline 1975 & 27,61 & 28,11 & 30,76 & 28,27 & 34,40 & 55,51 & 32,84 & 46,44 \\
\hline 1976 & 28,22 & 24,81 & 29,03 & 23,60 & 34,88 & 50,86 & 32,87 & 42,01 \\
\hline 1977 & 27,65 & 21,54 & 25,35 & 21,18 & 34,22 & 41,58 & 31,59 & 35,04 \\
\hline 1978 & 26,74 & 21,61 & 24,42 & 20,03 & 34,53 & 45,86 & 31,52 & 37,74 \\
\hline 1979 & 24,93 & 17,81 & 21,41 & 22,75 & 29,52 & 32,34 & 27,56 & 29,41 \\
\hline 1980 & 19,39 & 12,48 & 24,06 & 18,41 & 24,69 & 27,43 & 24,33 & 24,54 \\
\hline 1981 & 21,88 & 15,69 & 25,31 & 20,40 & 25,94 & 26,89 & 25,47 & 24,78 \\
\hline
\end{tabular}

* Coeficiente de Mortalidade Neo Natal a Infantil Tardia por 1000 nascidos vivos FONTE: SEADE

Seção de Estatística - SHS Gabinete - 24/06/83 
TAEELA 14 - PFINCIPAIS CAUSAS DE WORTE NA AREA CENTPAL

MENOPES DE I ANO - 1.981

$C A \cup S A S$

TOTAL

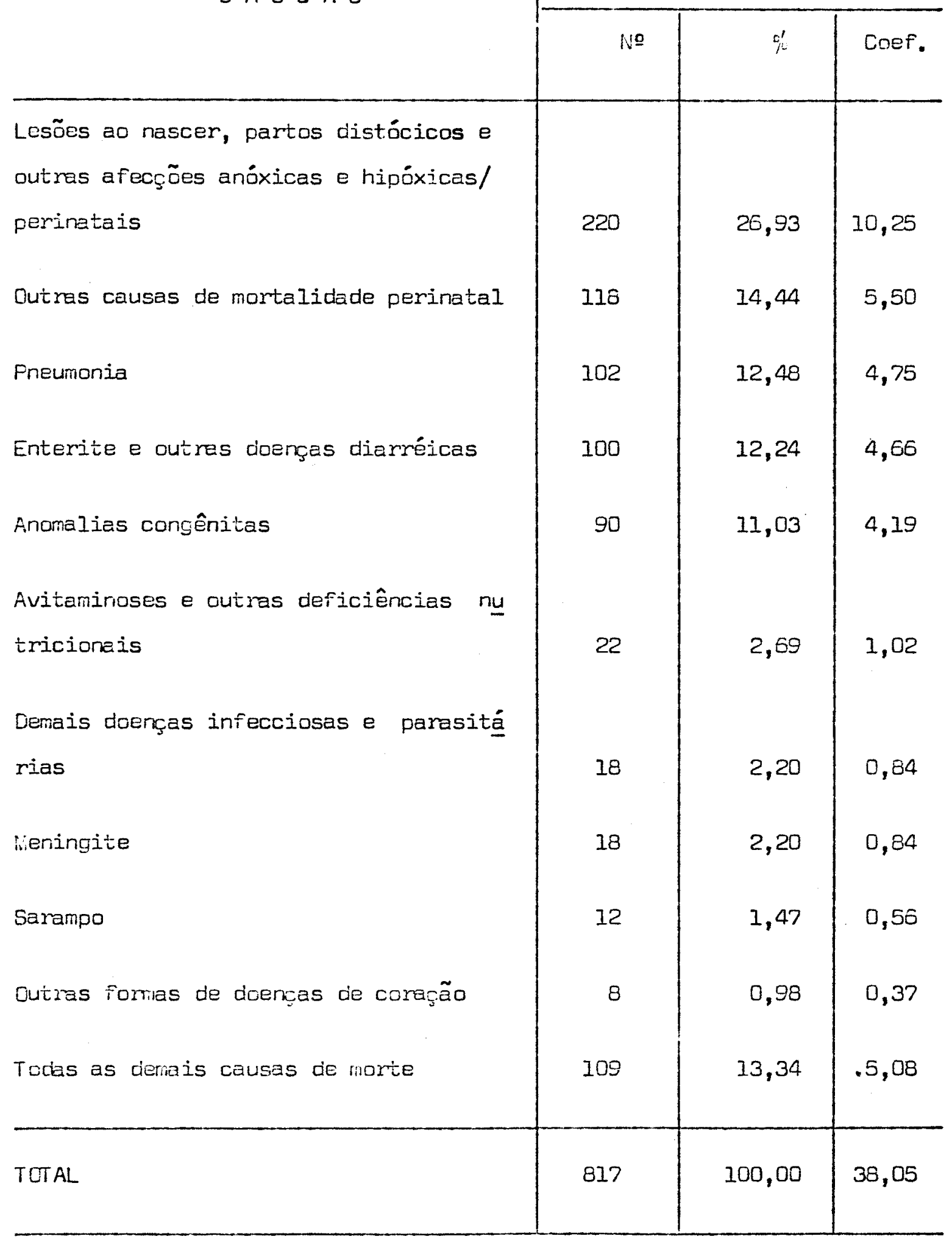


TABELA 15 - PRINCIPAIS CAUSAS DE WIORTE NA AFEA INTEFU:EDIÁRIA MENORES DE 1 ANO - 1.981

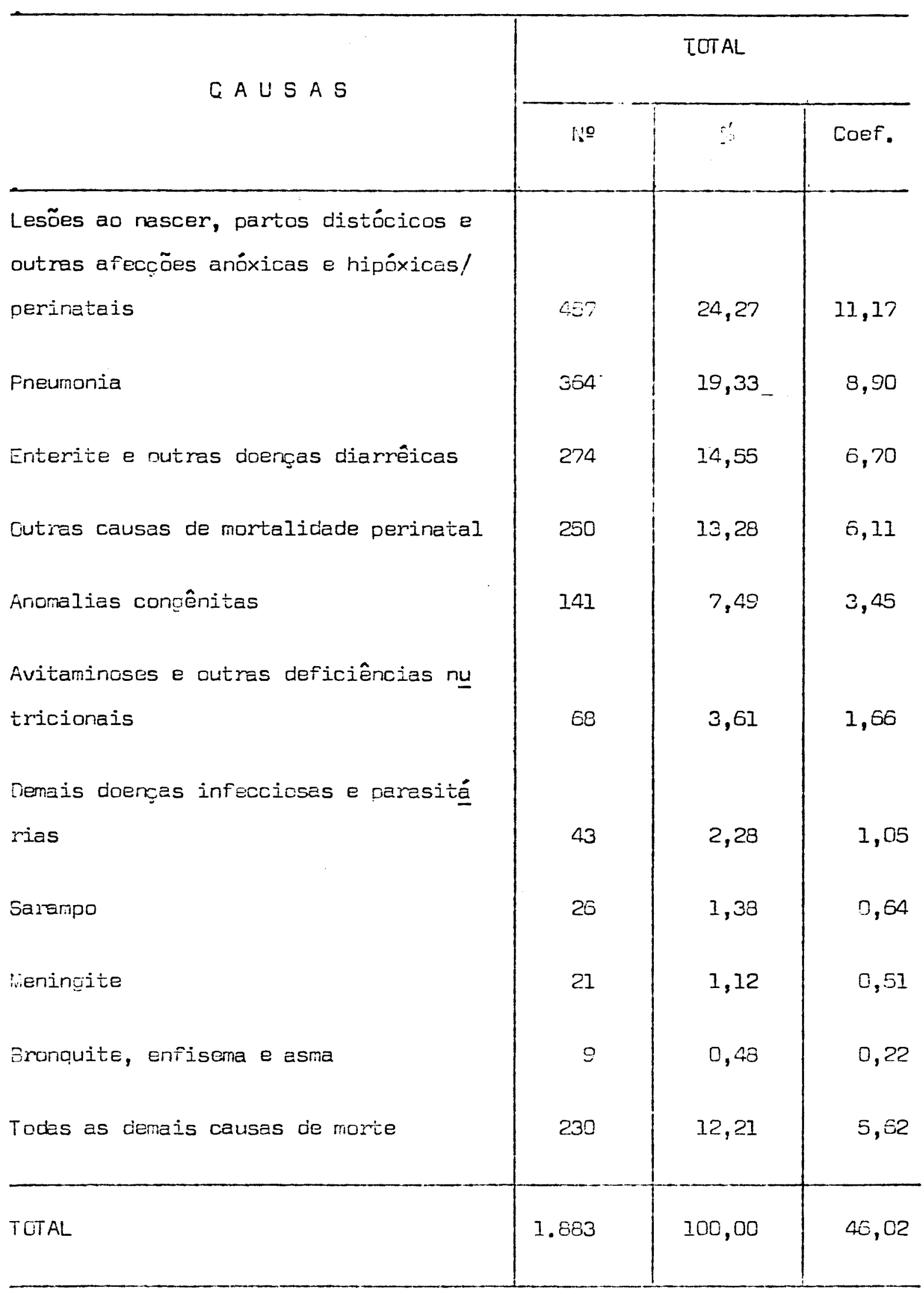


TAEELA 16 - PRINCIPAIS CAUSAS DE MORTE NA AFEA PERIFEFICA

WENOPES DE I ANO - 1.991

\begin{tabular}{|c|c|c|c|}
\hline \multirow{2}{*}{$C A \cup S A S$} & \multicolumn{3}{|c|}{ TOTAL } \\
\hline & № & $\%$ & Eoef. \\
\hline Pneumonia & 2.012 & 21,42 & 11,37 \\
\hline $\begin{array}{l}\text { Lesões ao nascer, partos distócicos e } \\
\text { outras afeccões anóxicas e hipóxicas/ }\end{array}$ & & & \\
\hline perinatais & 2.006 & 21,36 & 11,34 \\
\hline Enterite e outras doencas diarréicas & 1.639 & 17,45 & 9,20 \\
\hline Qutras causas de mortalidade perinatal & 1.062 & 11,31 & 6,00 \\
\hline Anomalias congênitas & 465 & 4,95 & 2,63 \\
\hline $\begin{array}{l}\text { Avitaminoses e outras deficiencias nu } \\
\text { tricionais }\end{array}$ & 393 & 4,18 & 2,22 \\
\hline $\begin{array}{l}\text { Demais doenças infecciosas e parasitá } \\
\text { rias }\end{array}$ & 374 & 3,98 & 2,11 \\
\hline Meningites & 169 & 1,80 & 0,96 \\
\hline Sarampo & 114 & 1,21 & 0,64 \\
\hline $\begin{array}{l}\text { Sintomas e estados mórbidos mal defi } \\
\text { nidos }\end{array}$ & 64 & 0,68 & 0,36 \\
\hline Todas as demais causas de morte & 1.094 & 11,66 & 6,18 \\
\hline TOTAL & 9.393 & 100,00 & 53,08 \\
\hline
\end{tabular}


perinateis $(24,27 \%$ ), as pneumonias ( $19,33 \%$ ) e as enterites e outras doenças diarréicas ( $14,55 \%)$.

Firialmente, na érea central, as lesões ao nascer, partos distócicos e outras afecr.ões nóxicas e hipóxicas perinateis ( $26,93 \%$ ), outras causas de mortalidade perinatal ( $14,44 \%$ ) e as pneumonias $(12,48 \%)$ constituem as principais causas.

Ao se analisar as principais causas de bibitos para todas as idades nas áreas Central, Intermediárias e Periféricas, nota-se que as doergas típicas de áreas mais desenvolvidas, como doenças isquêmicas do coração, tumores malignos, dnengas cérebro-vasculares coexistem com doencas mais encontradiças em áreas sub-desenvolvidas, como enterites, pneumonias, outras doenças diarréicas, demonstrando a presença de popula ções com características bem distintas nestas reniões.

\section{$\underline{6.6}-\underline{\text { IORBIDA.DE }}$}

Os poucos dados de morbidade são de difícil obtenção e não são totãmente confiáveis, visto que as coletas e a obtencão dos mes mos são irrequlares.

0 controle das doencas transmissiveis, devido o que repre senta em temos de saúde pública,possui a mais alta prioridade nos progra mas oficiais do governo. E, através do Sistema de Vigilância Epidemio Iọ́ica implantado pela Secretaria de Estado da Saúde, que temos as melho res informações através do controle e registro de doenças transmissiveis de notificação compulsória. Porém, essas informações não são de coriple ta credibilidade.

As doences trensmissiveis de notiricaça compulsória para - nosso Estado são:

- febre amarela

- peste

- cólera 
- variola

- hanseníase

- tuberculose

- poliomielite

- tétano

- doença meningocócica e outres meningites

- raiva humana

- febre tifóide

- sarampo' (casos internados em hospitais)

- leishmaniose visceral

- leishmaniose cutâneo -mucosa

- encefalite por arbovírus

- esquistossomose

- malária

- doença de Chacas (forma aguda)

- difieria

A Fundação SEADE, em 1979, selecionou uma amostra de 11.379 pacientes de um total de 720.000 internados no Município de São Paulo em amostra de 4 meses do ano, baseados em boletins da Coordenadoriade Assistência Hospitalar e da Vigilância Epidemiológica (Tabela 17).

Os dados encontrados revelam que o parto normal $e$ as causas obstétricas diretas constituem-se na principal causa de internacão, sezuidas das doenças respiratorias, doenças do aparelho digestivo, doenças infecciosas intestinais, neoplasias e doencas cardíacas. 
TABELA 17 - MORBIDADE HOSPITALAR DOS PACIENTES EGFESSOS, POR MESES DE COLETA, SEGUNDO OS DIAGNÓSTICOS PARA O MUNICIPIO DE SÃO PAULO - 1979.

\begin{tabular}{|c|c|c|c|c|c|c|}
\hline \multirow[b]{2}{*}{ LISTA DE DIAGNÓSTICO } & \multirow[b]{2}{*}{ JAN. } & \multirow[b]{2}{*}{ ABR. } & \multirow[b]{2}{*}{ JUL. } & \multirow[b]{2}{*}{ OUT. } & \multicolumn{2}{|c|}{ TUTAL } \\
\hline & & & & & Ne & $\%$ \\
\hline Parto Normal & 431 & 456 & 409 & 420 & 1.716 & 15,08 \\
\hline Causas Obstétricas diretes & 344 & 358 & 349 & 318 & 1.369 & 12,03 \\
\hline Sinais, Sintomas a Afec & & & & & & \\
\hline ções mal definidas & 384 & 301 & 270 & 331 & 1.286 & 11,30 \\
\hline Outras doenças do aparelho & & & & & & \\
\hline respiratório & 225 & 247 & 302 & 263 & 1.037 & 9,11 \\
\hline Doenças de outras partes & & & & & & \\
\hline do Aparelho Digestivo & 149 & 173 & 199 & 162 & 683 & 6,00 \\
\hline Doenças Infecciosas Intes & & & & & & \\
\hline tinais & 152 & 103 & 95 & 75 & 425 & 3,73 \\
\hline Doença do Aparelho Urinário & 112 & 93 & 88 & 122 & 415 & 3,65 \\
\hline Neoplasmas & 77 & 107 & 102 & 101 & 387 & 3,40 \\
\hline $\begin{array}{l}\text { Doenças da circulação puI. } \\
\text { monar a outras formas de }\end{array}$ & & & & & & \\
\hline doença do coração & 84 & 106 & 89 & 104 & 383 & 3,37 \\
\hline Doenças endócrinas a Meta & & & & & & \\
\hline bólicas e Transtornos & 53 & 43 & 56 & 44 & 196 & 1,72 \\
\hline Demais causas & 781 & 855 & 893 & 953 & 3.482 & 30,61 \\
\hline$T O T A L$ & 2.792 & 2.842 & 2.852 & 2.893 & 11.379 & 100,00 \\
\hline
\end{tabular}

FONTE: - SEADE - Anuário Estatístico do Estado de São Paulo - 1980 
o crescimento vertiginoso do Município de São Paulo não foi acompanhado de um proporcional aumento dos leitos regionalizados devi do, principalmente, à ausência de uma política edequada na área de saúde, onde se permitiu que interesses particulares se sobrepusessem aos da comu nidade.

Observa-se uma grande concentreç̃o dos hospitais ne área central da Capital atingindo indices de 13,2 leitos cerais por 1000 habitantes, enquanto que encontramos 4,6 e 1,1 leitos por 1000 habitan tes, resnectivamente, nas áreas intermediária e periférica.

Na área central e intermediária quase todos os subdis tritos e distritos de paz possuem 1 hospital e o observado na área perifé rica é que dos 27 subdistritos, 10 não possuem um só leito hospitalar. Além da falta de racionalização na construção e distribuição dos leitos hospitalares no kunicípio de são Paulo, outras dificuldades como fatores sociais e econômicos, distância e dispêndio de tempo, sistema de transpor te obsoleto fazem com que a pooulação que habita a área periférica tenha dificuldade de acesso aos recursos assistenciais, princinalmente os hos pitalares.

Fiesumidamente, podemos dizer que o atendimento hospitie lar no luunicipio de São Paulo não é uniforme. E descoordenado, sem rạ cilidade de acesso, desintegrado, não regianalizado e, por isso mesmo, ir racional e mais dispendioso. 


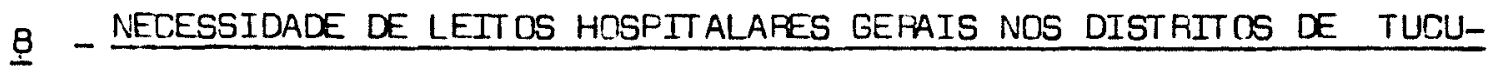 RUVI, VILA MARIA E FFEGUESIA DO O'}

Conforme parecer do Professor Odair Pacheco Pedroso (6), patrono da Administração Hospitalar em nosso pais, a determinação do número de leitos de uma comunidade é uma tarefa das mais difíceis.

lia literatura nacional encontramos dados como os afir mados pelo Professor Fezende Puech de 4 leitos/ 1000 habitantes em popu lação urbana.

Na literatura estrangeira, os valores predominantes encontrados são os Norte Americanos e que são subsidios importantes e valicsos para a determinação de leitos hospitalares.

Estudos de Stone ( 8 ) mostram que apesar da maioria dos autores considerarem 5 leitos por 1000 habitantes como valores sig nificativos, não explicam como obtiveram esse valor.

Stone ( 8 ) afima que não existe padrẽo fixo de lei tos por 1000 habitantes, mas que somente pelo exame cuidadoso de uma gama de fatores é aue se pode avaliar o número de leitos necessários pa ra uma determinada área.

Deveriam ser levados em consideração:

- o número e classificação dos leitos existentes;

- o vulto das relações de pesscas que agurdavam vaga para internação;

- o número médio de dias de permanência de cada classe de pacientes;

- o número de casos de emerôencia cuja admissão tem sido recusada;

- o tipo e crescimento da população;

- o número de óbitos e suas causas; 
- as profissões predominantes e os seus riscos para a saú

de;

- o sistema de habitação familiar e individual;

- a atitude dos médicos com respeito à admissão de pacien tes ao hospital e

- o desenvolvimento que foi dado aos serviços de ambulató rios.

Em 1946, foi aprovado pelo Governo dos EEUU, a lei HillBurton, na qual o Governo Americano auxiliaria os Estados Norte- America nos na construção de hospitais, desde que o coeficiente de leitos não uI trapassasse de 4,5 a 5,5 leitos por 1000 habitantes, dependendo da densi dāde de população da área a ser favorecida.

A Comissão que estudou os recursos e necessidade hosoita lares de kichigan, nos EEUU, obtem coeficientes similares aos dos outros autores, afirmancio que a fórmuia apresentada não fornece uma resposta in tegral ao problema do cálculo das necessidiades em leitos hospitalares, devendo-se sempre levar em consideração todos os múltiplos fatores lo cais.

De acordo com a Comissão de Michigan, a necessidede em leitos hospitalares gerais numa determinada área depende da quantidade atual e futura de doenças cujo tratamento requeira hospitalização.

0 coeficiente leito-óbito poderá ser alterado de tempos em tempos, mas sua flutuação não será significativa em pequenos perío dos. For essa outra sistemática, também os valores oscilam em 4,5 leitos por 1000 habitanies.

O Comitê de Técnicos em Organizą̧ão ne Assistência kédi ca, da organização Nundial de saúde (5), em 1957, coloca " a impos sibilidade de recomendar uma relação direta entre o número de leitos e a de habitantes, pois as necessidades dependem de muitos fatores, entre os quais citam os seguintes: 
1.) a distribuição da população por idades;

2.) o nível geral de vida, hábitos, condições de habitação e os meios de transporte;

3.) a densidade populacional, já que as zonas urbanas necessitam

de mais leitos por mil habitantes que as zonas rurais;

4.) a incidência de doenças e traumatismos;

5.) a qualidade de assistência proporcionada, fora dos hospitais, por mé dicos, em consultórios particulares e pelos centros sanitários e

6.) o sistema adotado para cada país para cobrir os castos de seus hospi tais, a legislação nacional e os sistemas de seguro social ".

Em dados do Conselho Consultivo da Admiristração de Saú de Previdenciária ( CONASP) em "Reorientação da Assistência à Saúde no Âmbito da Previdência Social " ( 1 ), estabeleceu-se que a necessidade de leitos excluindo-se os d psiquiatria teria como base 1,8 leitos ce reis/ 1000 habitantes. Em nossa opinião consideramos ainda que tais proporções são frequentemente enganosas $e$, o que idealmente se tem ouse determinar é a relacão existente entre os servigos concretos de assistên cia e o número de indivíducs que necessitam esses serviros.

Fare efeito de planejamento utilizaremos os valcres re comendados pelo CONASP, de 1,8 leitos gereis/ 1000 habitantes.

A população dos Distritos de Vila liaria, Freguesia do C' e Tucuruvi tem para 1983 ume estimativa populacional de 1.602.341 ha bitantes e, se aplicarmos o valor CONASP. necessitamos para essa região 2.884 leitos.

Em levantamento realizado em diversas fontes e nos hos pitais existentes nos 3 Distritos, independente de serem conveniados ou particulares, quanto ao número de leitos e especialidades, encontramos números altamente contraditórios em Clínica Médica, Cirurgia, Fediatria e Ginecologia Obstetricia, num total aproximado de 1000 leitos. 
o Projeto do Complexo Hospitalar do Nandaqui procura a melhor utilização de estruturas já pré-existentes e antes de preten der ser a solução do número de leitos para a região, é uma proposta de colocaçẽo de 750 leitos à disposição da comunidade da região enfọ cada podendo, em condições excepcionais, atingir até 900 leitos.

Esses 750 leitos serão divididos em 200 leitos de PE diatria, 200 leitos para o Instituto de Pneumologia ( para internação de pneumopatias específicas e não específicas), 100 leitos de kater nidade, 120 leitos de Clínica hédica, 80 leitos de Cirurgia e 50 lei tos de retaguarda de Pronto Socorro.

O número de leitos estabelecidos não foi obtido atra vés de fórmulas ou parâmetros nacionais ou internacionais, mas basi camente atendendo ao objetivo inicial do projeto, utilizando recur sos existentes, meximizando e os otimizando e encerrando a ociosidade de leitos existentes nos hospitais que compõem o Complexo, conforme demonstretivo nos Capítulos I e II.

Importa ainda, dentro do estudo desenvolvido, a con dição de tuberculose e suas intercorrências. A tuberculose. repre senta importante parcela em saúde pública e as intercorrências havi das com pacientes tísicos no Parque Hospitalar do Nandaqui e sem pos sibilidade de resolugão por este Hospital, encontra grande dificulde de na aceitação e transferência para outros hospitais com maior capa cidade resolutiva, trazendo prejuizos enormes na assistência hospita lar dos mesmos.

0 Complexo Hospitalar integrado, então já uno, teria em sua composição os prédios dos atuais Hospital Infantil da Zona Norte, Pavilhões Miguel Pereira e Leanor fiendes de Barros do Parque Hospitalar do flandaqui além de númerosos prédios menores que abrigam atualmente áreas administrativas ou residências de funcionários. 
Analisando a que atualmente temos e, dependendo de estudos mais minuciosos que deverão ser realizados pela Coordenadoria de Assistência Hospitalar e Diretoria dos Hospitais Infantil da Zona Norte e Parque Hospitalar do liandaqui assim ficará a nova estrutura:

- Hospital Infantil da Zona Norte: será transformado no Instituto de Pneumologia do Complexo Hospitalar, recebendo pa cientes adultos, masculinos e femininos (ambos os sexos ) portadores de tuberculose, e, ampliando sua assistência a todas as patologias pulmonares indistintamente, tomando-se o primeiro Hospital estatal com essas características.

Teré 200 leitos e necessitará de reformas que visa rão dotar cada unidade de internação de melhor conforto térmico,acús tico, de ventilação e colocação de 1 vaso sanitário e 1 chuveiro para um méximo de 6 pacientes.

Contará o Instituto com salas de Diretoria clíni ca, Diretoria Administrativa, Diretoria de Enfermagem, Sala de Reu niões, Sala de Projeções e Capela.

A redução de 200 leitos para o Instituto em compa ração aos aproximados 250 leitos que atualmente funcionam no Paví Ihão higuel Pereira será compensada por agilização e melhoria da ca pacidade resolutiva com melhor funcionamento des atividades desenvol vidas pela Unidade Fadiolórica, Secão de Patologie Clínica e Anatomia Patológica e implantação de clínicas de especialização associades a um aumento quantitativo e qualitativo do pessoal médico e de enferma gem.

O atual prédio de Patologia do Hospital Infantil da Zona Norte em total abandono, com exceção da pequena área que abrị ga o necrotério, deveré passar por reforma e se constituirá no Labora tório Central do todo o Complexo, desenvolvendo atividade que dará 
autonomia ao conjunto, encaminhando ao Instituto Adolfo Lutz apenas os exames de maior complexidade, como por exemplo, estudos imunológicos.

- O Pavilhão Leonor Miendes de Barros, hospital com construẽão inicial próprio para Pediatria, receberá os pacientes do Hospital Infantil da Zona Norte e, após criteriosa avaliação, manterá os pacientes infantis de tuberculose.

0 Hospital Infantil terá 200 leitos distribuidos em 6 unidades de internação, sendo uma para pacientes de tuberculose infan til e suas intercorrências, uma unidade de retaguarda para o Pronto So corro Infantil, 2 unidades para lactentes, I unidade para pré- escolar e 1 unidade para escolar, mantendo ai leitos destinados para assistên cia aos adolescentes, leitos estes, únicos em hospitais da Secretaria de Saúde que recebem pacientes pediátricos.

- Pavilhão kiguel Pereira - atualmente destinado à internação dos pacientes tuberculosos adultos, deverá ser totalmente modificado na sua estrutura física para atender ao novo planejamento e, portanto, é neste Pavilhão que as reformas serão mais necessárias. Basicamente serẽo utilizadas como referência as " Normas e Padrões de Construçōes e Instalações de Serviço de Saúde do Winistério da Saú de" ( 3$)$

0 pretendido ficaria com a seguinte distribuição:

Sub-Solo - Serviço de Nutrição e Dietética com Cozí nha, Fefeitório, Dispensa e Chefia;

Andar Térreo - Unidade de Fronto Socorro, Unidade de Ambulatório (com Eanco de Sangue agregado ), Unidade de Padiologia e Diretoria Adninistrativa do Pavilhão liguel Pereira;

10 Andar - seriam manitidos o Anfiteatro Principal e

2 unidades de internação que necessitam reformas para retaguarda ... do Fronto Socorro num total de 50 leitos ( 25 masculinos e 25 femininos) e, onde atualmente funciona precariamente a Unidade Radiológica, im plantariámos uma excelente área para conforto médico, com quartos de repouso para os médicos plantonistas;. 
29 Andar a atual unidade de Centro Cirúrgico aí locali zada seria adaptada com poucos recursós e obras, em ótimo Centro obsté trico e, uma das alas daria lugar ao novo Centro Cirúrgico com 6 salas de Cirurgia. Na outra ala situar-se-á o Centro de haterial Estere lizado e uma Unidade de Terapia Intensiva com 10 leitos e Centro de Re cuperação Pós-Anestésica;

30 Andar - duas unidades de internação num total de 80 leitos para clínica cinúrgica;

40 Andar - duas unidades de internação de maternidade com 100 leitos e berçário de patológicos, isolamento e prenaturos e 50 Andar - duas unidades de internação para clínica mé dica, num total de 80 leitos.

Todas as Unidades de Internação passarão por reformas, dotando os quartos e enfermarias de sanitários e chuveiros, mantendo sempre a disposição de no máximo 6 pacientes se utilizarem de 1 chuvei ro e 1 sanitário. Serão observados as necessidades de pontos de oxi gênio, vécuo e ar comprimido, sistema de inter-comunicação intema e comunicação paciente-enfermagem, todos atualmente inexistentes.

Definidas as finalidades dos 3 grandes hospitais, cabe ria equacioner o suporte de apoio para o funcionamento e bom desempenho dos mesmos:

- Unidade de Administração Central - Localizar-se-á em área o mais central e equidistante dos prédios de internação e que é constituido de um prédio que abrigava a Caixa Beneficente do liandaqui e outres casas de antigos moredores do Parque.

Nesta área deverão se Iocalizar a Diretoria do Complexo Hospitalar; Posto de Serviço do Banco do Estado de São Paulo; Clausura e Serviço de Pessoal.

- Unidade de Serviços Gereis - tembém o objetivo será a centralização de áreas físicas, pessoal e equipamentos, somando-se e 
otimizando os recursos.

a.) Na área do atual Hospital Infantil da Zona Norte e futuro Instituto de Pneumologia funcionará:

1.) Lavanderia Central - de recente e adequada construção, atendendo pa drões técnicos recomendados, podendo com pequenas adaptações de maquiná rios, lavar até $4000 \mathrm{Kgs} / \mathrm{roupa} / \mathrm{dia}$.

2.) lianutenção Céntral - aproveitamento as oficinas já existentes e ada ptando um prédio contínuo às mesmas, e que atualmente está abandonado, onde funcionava a antiga lavanderia. Assim poderiamos desenvolver etribuições de mecầnica, hidráulica, carpintaria e pintura e

3.) Vestiário - junto à Portaria, atenderá aos funcionários do novo Ins tituto.

b.) Na área do Farque Hospitalar do Nandaqui:

1.) Vestiário Central - próximo ao conjunto da Unidade Administrativa já funciona e assim será mantido até a construção de um vestiário para todo Complexo, junto à Portaria Centrel. O vestiário atualmente exis tente é una adaptação de um antigo Pavilhão de Internação.

2.) Almoxarifado - já instalado precáriamente em parte do prédio onde funciona a lavanderia do Parque Hospitalar. Com a mudança da mesma para a nova lavanderia, toda área física será destinada ao almoxarifado do Complexo.

As cozinhas, atualmente em número de 3 para os dois Hospitais, seriam integradas numa única, que se localizará no sub- solo do Pavilhão Niguel Pereira, que é a maior e com reformas de área física e substituição de equipamentos obsoletos poderá perreitamente atender a todo Complexo como cozinha geral.

A atual cozinha do Pavilhão Leonor Mendes de Barros se rá adaptada para elaborar dietas para lactentes pontificando as ativida des de lactário. - Por estar localizado no próprio prédio do Pavilhão terá facilitada a distribuição de mamadeiras preparadas e a recepção das usadas. 
A cozinha atualmente existente no Hospital Infantil de Zona Norte irá funcionar no Instituto de Pneumologia apenas como rece ptador e distribuidor cas refeições elaborados na cozinha central.

Restariam ainda 3 áreas técnicas para o fechamento das necessidades do Complexo: Unidade de Anatomia Patológica, Unidade de Patologia Clínica e Serviço de Arquivo liédico e Estatística.

A Unidade de Anatomia Fatológica será a que-atualmente já existe no Parquie Hospitalar do liandaqui e que com seus recursos po de atencier a todo Complexo. oferece boas condič̃es, dispensando qualquer alteração.

A Unidade de Paíologia Clínica como já foi dito ante riormente será instalada no prédio da Anatomia Patológica do Hospital Infantil da Zona Norte.

Finalmente, o Serviço de Arquivo Médico e Estatística teré sua localização centrada, após reforma e adaptação, na antiga oficina do Parque Hospitalar do handaqui, local de construção sólí da, térrea, onde funcionará Cheria, Estatísicica Védica e Administrati va, Arquivo Centrel e licro-filmarem, sendo os Fegistros e Informa cões descentralizados para cada um dos 3 Hospitais.

Faz parte do Complexo, o Centro de Convivência Infan til (C.C.I.), atualmente já único para os dois Hospitais, numa casa assobredada, junto à Portaria do Parque Hospitalar, Com o funciona mento do Pronto Socorro e aumento do fluxo de ambulâncias, as crian cas que frequentam o centro de Convivência Infantil não terão, confor me nosso desejo, seguranca e tranquilidade. Assim sendo, o C.C.I. seré deslocado para 2 residências térreas, confortáveis, antigas mora dias de funcionários que, com pequenas adaptações, se tornarão óti mas para o uso, com ampla área verde, onde as crianças poderão desen volver atividades pedagógicas, jardinagem, horta e marcenaria. 
Uma outra residência, antiga moradia do Administrador do Hospital Infantil da Zona Norte, que serviu para o funcionamento do Centro de Convivência Infantil deste Hospital até a união das crê ches, terá suas instalações adaptedas para o funcionamento do 10 ambu latório descentralizado do Hospital do Servidor Público Estadual "Francisco Morato de Oliveira ".

A atual Administração projetou e irá destinar área de cerca de 3000 metros quadrados, sem utilização anterior, para servir como início de desenvolvimento de horta comunitária para seus funcio nários e está pleiteando a retomada de cerca de 15.000 metros quadra dos, pertencente ao Parque Hospitalar dp Vandaqui, cedidos em comoda to a terceiros em 1959, onde funciona um clube privado. 0 objeti vo desta retonada seria a utilização do mesmo cono clube para os fun cionários do Complexo e Secretaria de Saúde. 
Da reunião da Organizaçẽo Panamericana de Saúde (CPAS) rea lizada em iashington de 7 a 9 de março de 1962, segundo Guimarẽes ( 2 )" al guns conceitos se destacam pela importância diretiva " e que são impartantes em nossa proposta. Afima ainda que "lios aspectos gerais estão a coor denå̃ã intra $E$ inter-institucional e a recionelização e, nos aspectos espe cíficos, incluem-se a integrarãa dos servigos bésicos de assistência médica dentro dos procramas nacionais e locais de saúde píblica ".

Em nosso estudo, o têrmo intẹração assume significado am plo e poderemos dividir esta integreção em 2 momentos distintos. Num 10 momento, a abordagem diz respeito à coordenar.ã̃o e integracão dos Hospitais Infantil da Zona Vorte e Parque Hospitalar do landaqui. Aqui, integrar significa reunir, juntar, incorporar os recursos humanos, financeiros, mate riais e físicos dos 2 Hospitais, colocando-os sob um único teto administrati vo, visando a melhor utilizacão destes recursos na viabilizacão do complexo Hospitalar do landaqui. Num 20 momento, cabe discutir o papel assistencial que o Complexo representará na área programática com as outras instituicões de saúde, e que estarão relacionadas ao novo Hospital. Visará a integre ção entre os Postos de Assistência lédica (PAlis), Centros de Saúde (C.Ss), Frontes Socorros (P.Ss ) e Hospitais da Fede Estadual e liunicipal dos Dis tritios de Tucuruvi, Vila laria e Freguesia do $\mathrm{O}^{\prime}$, quer a nível ambulatorial, quer a nivel hospitalar, procurando dar uma cobertura assistencial a quem se dirige a estes servicos. Atrevés de convênio que deverá ser fimado en tre o Hospital do Servidor Píblico Estadual " Frencisco lorato de Cliveira " e o Complexo Hospitalar do landaqui se pretende ampliar esta cobertura aos funcionárís públicos estaduais e dependentes residentes na área em foco, es tabelecendo-se um princípio de regionalização. 
De acordo com lic Nermey ir Riedel (4) "en sua expres são mais simples, aplicada à área de saúde, regionalização refere-se ao estabelecimento de relações de trabalhó entre várias instituiç̃ões e programas de saúde dentro de uma área geográfica definida ".

Com a idéie de integração e regionalização procura-se minorar a existência de um déficit quantitativo geral de assistência , ou seja, uma baixa cobertura médico-assistencial da população ạravada qualitativamente pela presença de deficiências estruturais e operativas dos serviços. Existem muitos serviços públicos, e mais um tanto de privados, que participam de prestação da assistência e, o que ocorre na prática é uma descoordenação entre os mesmos, onde os hospitais não tem nenhuma integração com os serviços da rede básica, fẹchando-se intra muros.

A utilização de sistemas anacrônicos de organização, - uso de métodos e técnicas administrativas ultrapassadas, agravadas por uma política financeira que não prioriza a saúde, Ieva a um fun cionamento ineficiente das instituições de saúde, maiores custos opera cionais, sub utilização de instalações e equipamentos, baixa produtivi dade e inadequada assistência.

$$
\text { Robayo ( } 7 \text { ) consider que " a modalidade regionaliza }
$$
da de organização dos serviços de saúde constitue a expressão técnicaadministrativa das inter-relações dos níveis de assistência".

Será o Complexo Hospitalar do handaqui o Centro em torno do qual gravitarão os recursos de saúde dos Distritos Sanitários de Tucuruvi, Vila liaria e Freguesia do o' e através do Instituto de Pneumologia, será mantida a referência estadual no atendimento ao tuber culoso.

As principais inter-relações institucionais são as que se seguem: 


\section{I. - Secretaria de Higiene da Prefeitura:}

A.) Rede Résica de Saúde:

a.I Postos de Assistência Wédica (PAW ) da Freguesia do D';

a.2 Postos de Assistência liédica (PAll) da Vila Maria e

a.3 Postos de Assistência liédica ( PAl!) ) de Tucuruvi

B.) Serviços de Energência:

b.1 Pronto Socorro liunicipal de Santana;

b.2 Pronto Socorro línicipal da Freevesia do O' e

b.3 Pronto Socorro liunicipal do viandaqui funcionando dentro do pró prio Complexo, mais especificamente no Pavilhão Miguel Pereira.

C.) Serviço Hospitalar

Hospital e haternidade Escola Vila Nova Cachoeirinha. Com o funcionamento da maternidade no Complexo Hospitalar do liandaqui será possivel a regionalização e hierarquização no etendimento à gestante, cabendo ao Complexo a estimativa assistencial de 8000 partos por ano em nível secundário, ficando à Maternidade Escola de Vila Nova Cachoeirinha, que possui melhor capacitação resolutiva e técnica, a responsabilidade na atenção terciária à.gestante, ou seja, o atendimento dos pacientes de alto risco com estimativa de 4000 partos anuais.

II. - Secretaria de Estado da Saúde

Rede Básica - representada pelos Centros de Saúde da região con siderada.

III. - Instituto de fssistência l'édica ao Servidor Fúblico Estadual ( IAl:SP ) 
área e prédio do Complexo para a instalação e funcionamento do lo ambu latório descentralizado para o atendimento do servidor público estadu al e seus dependentes moradores da região nerte de Capital, facilitan do o acesso, dando condições de assistência mais rápida e com menor custo ao usuário e diminuindo a demanda existente nos Ambulatórios cen tralizados, que funcionam no Hospital do Servidor Público Estadual. Inicialmente atenderé nas especialidades de Clínica l'édica, Pedietria e Einecologia-Obstetrícia utilizando todos os serviços técnicos e ad ministrativos do Complexo como apoio, referência e auxílio.

Por outro lado, as novas Unidades de Patologia Clíni ca, Padiologia, Ambulatório de Especialidades e Anatomia Patológica com melhor adequação de área física, equipamentos e pesscál além de melhorarem a atividade assistencial médica do próprio Hospital, serão utilizadas para o atendimento da rede básica lunicipal e Estadual dos Distritos Sanitários enfocados, melhorando a capacidade resolutiva desses serviços e consequentemente melhor atendendo a população de Vila laria, Tucururvi e Freguesia do $0^{\prime}$.

$$
\text { Com a assinatura de convênio e oficialização }
$$
27/10/83 do Frograma de Assistência Integrada de Saúde (PAIS ) envol vendo o Vinistério da Saúde, INAMPS e Secretaria de Estado, o Comple xo Hospitalar deverá estar preparado também para a assistência preví denciária. 
63.

\section{1-CRONOGRAM:A DE IMPLANTACAO DO COMPLEXO HOSPITALAR DO MANDAQUI}

A proposição de funcionamento do futuro Complexo Hos pitalar do Mandaqui representa um desafio profissional, dada a comple xidade de fatores de ordem política, econômica e principalmente insti tucional, devido as políticas diferentes vigentes nas instituições componentes do setor de saúde.

Serão destes fatores que dependeremos para o estabe lecimento de um cronograma operacional do Projeto.

Considerando-se que a Livre iniciativa da Diretoria do Complexo tenha amplo respaldo dos Órgãos ao qual se subordina, te remos a implantação dividida em 4 fases distintas:

$$
\begin{aligned}
& \text { A - Curtissimo Prazo até } 30 \text { dias } \\
& \text { B - Curto Prazo de } 30 \text { dias a } 6 \text { meses } \\
& \text { C - Médio Prazo de } 6 \text { meses a } 12 \text { meses } \\
& \text { D - Longo Prazo de } 12 \text { meses a } 18 \text { meses }
\end{aligned}
$$

A - Curtíssimo Prazo (até 30 dias )

\section{Pavilhão Leonor Miendes de Barros}

1. 1 Unidade de Internação Pediátrica

1.2 Pronto Socorro Infantil

2. Pavilhão Uiguel Pereira

2.I Pronto Socorro Municipal do liandaqui

2.2 Diretoria Técnica

2.3 Diretoria dos Serviços Administrativos

2.4 Setor de Comunicações 
3. Prédio onde funcionava a Sociedade Beneficente e Residêncies

3.1 Seção de Pessoal

3.2 Serviço de Finanças

3.3 Setor de Zeladoria

3.4 Seç̃o de haterial e Fatrimônio

3.5 Contadoria Seccional da Secretaria da Fazerida

3.6 Posto Bancário

4. Atividades Administrativas de Apoio

4.1 Centralização das Sub-Frotas

4.2 Centralização das Atividades das Oficinas

B - Curto Prazo ( 30 dias a 6 meses )

1. Pavilhão Miguel Pereira

1.I Unidade de Ambulatório (Especialidades )

1.2 Unidade Radiológica

1.3 Unidade de Centro Cinúrgico

1.4 Unidade de Centro Obstétrico

1.5 Unidade de Centro de haterial Esterelizado

1.6 Unidade de Intemação ( 50 fo dos leitos )

1.6.1 latemidade

1.6.2 Clínica kiédica

1.6.3 Clínica Cinúrgica

2. Pavilhão Dr. Antonio Guião Vestiário Centralizado dos funcionários

3. Hospital Infantil da Zona Norte

3.I Instituto de Pneumologia

3.1.I Unidades de Intemação ( 200 leitos)

3.1.2 Unidade de Pronto Atendimento e Ambulatório 
4. Prédio do Necrotério e Anatomia Patológica do Hospital Infantil da Zona Norte Laboratório de Patologia Clínica Fèrional

5. Centro de Convivência Infantil Centralizado

6. Lavanderia do Hospital Infantil da Zona Norte Centralizada

L - Eédio Prazo ( 6 meses a 12 meses )

1. Pavilhão Miguel Pereira Reforma e Centralização do Servị̧o de Nutrịão e Dietética

2. Favilhão liandaqui I Futura Biblioteca e huseu

D - Longo Prazo ( 12 mieses a 18 meses )

1. Pavilhão Miguel Pereira

1.1 Unidades de Internação ( $50 \%$ )

1.1.1 Clínica Médica

1.1.2 Clínica Cirúrgica

2. Dutras Obras Necessárias

2.I Construção de Depósito de Lixo

2.2 Almoxarifado Central. 
Delineadas as modificarões na estrutura física, a sua execução deverá ocorrer sem prejuízos e diminuição das atividades atualmente desenvolvidas peles Instituicões.

Partindo da elaboração de um novo Regulamento per mitir-se-á implantação de uma estrutura administrativa que venha aten der as necessidades organizacionais do Complexo a ser instalado, sem pre objetivando a utilizacão máxima dos recursos disponíveis e de acor do com as normas estabelecidas pela Coordenadoria de Assistência Hospi talar.

Assim é que o cumprimento das finalidades propos tas deveré ter em suas linhas principais o modelo de estruture que se segue:

\section{DIFETCRIA DE DEPARTAIAENTO NIVEL I}

Estão subordinados técnica e administrativamente.

à Diretoria de Departamento 5 grandes Divisões:

I. Divisão Mídica

II. Divisão de Enfermagem

III. Divisão de Serviço Paramédico

IV. Divisão de Serviços Complementeres de Diagnóstico e Terapêutica

V. Divisão de Serviços Administrativos

I. DIVISATO UEEDICA

1. Serviço de Pediatria

2. Servico de Tisio-fneumologia

3. Serviço de Clírica ivédica

4. Serviço de Ginecologia e Obstetrícia

6. Serviço de Clínica Cirúrgica 


\section{DIVISAOO DE ENFEFIAGEE!}

1. Enfermagem Hospitalar

2. Enfermagem de Saúde Pública

III. DIVISÃO DE SEPNICOS PAFAIKEDTCOS

1. Serviço de Arquivo iédico e Estatística

2. Servirgo Social liédico

3. Serviço de Nutrição e Dietética

4. Farmácia

5. Psicologia Clínica

6. Serviço de Documentação Científica

IV. DIVISÃO DE SEFVICOS COWPLERENTAPES DE DIAGNUEST ICO E TERAPEUT ICA

1. Serviço de Radiolocia

2. Serviço de Hemoterepia

3. Servigo de Anatomia Patológica

4. Serviço de Patologia Clínica

V. DIVISAOO DE SERVICOS ADNINIST RATIVOS

1. Serviço de Pessaal

2. Serviço de Finanças

3. Serviço de liaterial e Patrimônio

4. Serviço de Atividades Gerais 


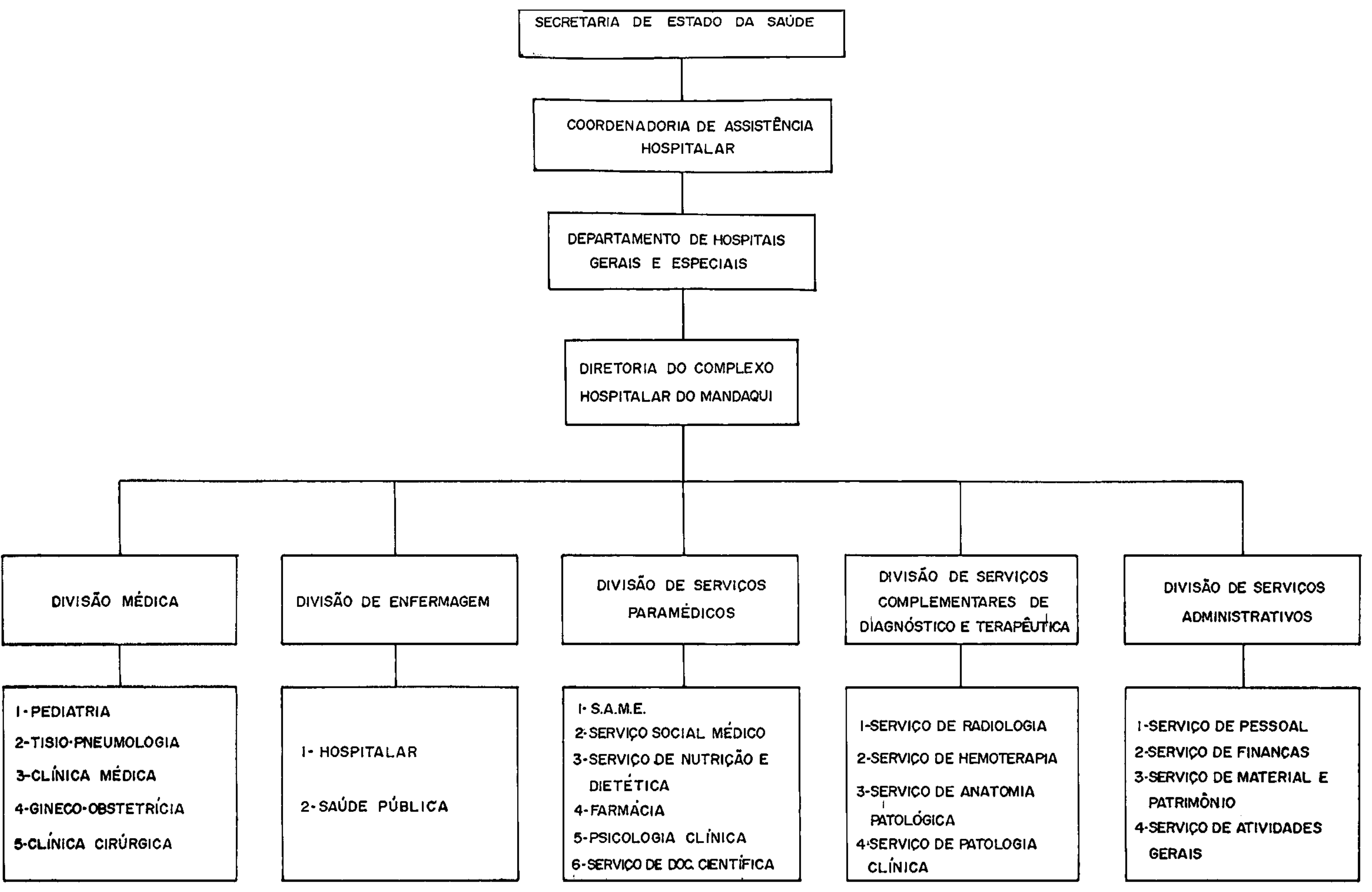


69.

13 CON:CLUSÃO

Apresentamos de acordo com o objetivo proposto um modelo possível e viável de integrarãa do Hospital Infantil da Zo na Norte e Parque Hospitalar do kandaqui, de finalidades distin tas, en um hospital geral de 750 leitos, o Complexo Hospitalar do liandaqui, Juntamente com a co-participação de outros recursos como os da Secretaria de Higiene e Saúde da Prefeitura de São Pau Io, do Hospital do Servidor Público Estadual "Francisco horato de Gliveira " e do Instituto Nacional de Previdencia Social, numa associação altamente desejada e não usual, ampliará as condi̧̧ões de assistencia hospitalar para os Distritos de Vila klaria, Nossa Senhore do $O^{\prime}$ e Tucuruvi e progressivamente a toda Região Norte do kunicíoio de São Faulo, podendo até se transformar num Hospi tal de Clínicas para a região. 
14 - FEFETEINCIAS BIBLIOGRAFICAS

1. CONSËHO CONSULTIVO DA AD:IINISTRAÇÃO DE SAÚdE PFEVIDENCIÁRIA. PIEorienta-ão de assistêncie à Saúde no ênbito da Previdência Sn ciel. 3a. ed. Fiio de Janeiro, 1983

2. GUI!:ACZES, Cid. Contribui-ão an Estudo nere Interrar os Servizos de Saúde na Fuiana. São Faulo, 1972 (Tese de Doutoremento - Faculdade de Saúde Pública - USP )

3. STiISTÉFIO DA SAUDE. lormas e Padrões de Construnões e Instelecõos de Semicos de Saúde. Erasilia, Ceniro de Documeritegão do linistério da Saúde, 1983.

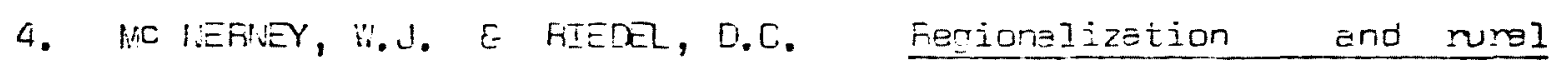
health care: an exneriment in three comunities. Ann A.rbor. , University of !ichigan, 1962. (Eureau of Hospital Áministre tion. Feseerch Series 2 )

5. URGANIZACÃ MUNDIAL DA SAÚDE. Función de lCs hos-itales er. IOS Grogramas de proteccion de le salud. Genetra, 1957, ( Eśrie de Informes Técnicos, no 122 )

6. FEUROSO, O.P. Hospital Dona Carolina lalheiros: Um haspital de comunidade. São Paulo, 1959 (Tese pera catédra - Faculjade Higiene e Seúde Pública - USP )

7. RDBAYC, Latge CEsউellands. Situeciones de CoDerture, niveles de zitención priréria. Ecletin de la coficina Sanitórie pansmeri cəna $?$ (6): 47e-492, iun. 1977.

8. STdVE, 1.E. Hinsnital croanization and Eoement. London, feter, 1952. 
1. ASSOCIAÇ̃o PAULISTA DE SAÚdE PÚBLICA. Textos de Saúde Pública. São Paulo, 1981 ( PREVSAÚde, no I)

2. BORBA, J.G. Subsídins para a melhoria de assistência médico hosoitalar no Estado de São Paulo: Centro Piloto de Leme. São Paulo, 1962. ( Tese apresentada à Faculdade de Higiene e Saúde Pública da USP )

3. CAFVALHO, Lourdes de Freitas. Determinacião das necessidades de leitos em hospitais gerais. Revista Faulista de Hospitais 25 (8): 341-370, ago., 1977 .

4. CARVALHO, Lourdes de Freitas. Assistência médica na área periférica de São Paulo. Revista Paulista de Hospitais 27 (12): 372-376, dez. 1979.

5. CONSELHO CONSULTIVO DA ADIINIST PAÇÃO DE SAÚdE PFEVIDENCIAFiIA. Plano de reorientacão da essistência à saúde no âmbito da Previdêncie Social. Rio de Janeiro, 1982.

6. DE STEFANo, Italo João. Hospital "São Luiz Gonzaga " - Jacanã da Irmandade de Santa Casa de liisericordia de São Faulo. São Paulo 1958. ( Trabalho apresentado à Faculdade de Higiene e Saúde Pública - Vestrado )

7. FUNDAÇÃC SISTE:A ESTADUAL DE AHALLISE DE DADOS. Anuário Estatístico do Estado de São Paulo - 1982. São Paulo, SEADE, 1983.

8. GUTMARÃES, C. Corpo clínico organizado é exigência do hospital de nossos dias. lied. Hosp. I (7): 43-6, 1958. 
9. GUIriARKES, C. Determinacão das necessidades de leitos em hospitais gerais. Revista Paulista de Hospitais $25(8): 341-370$, ago, 1977.

10. INSTITUTO NACIONAL DE ASSISTENCIA NEDICA DA PREVIDENUCIA SOCIAL. Programa de reorientacão da assistência odontolónica. Rio de Janeiro, liPAS/CCS, 1983.

11. JATENE, Adib Domingos et. al. Assistência à saúde na região metropolitana de São Paulo - Erasil. Washington, D.C., 1981 ( Trabalho apresentado à Feunião Fegional alrs/OPS, sobre desen volvimento de Serviços de Saúde nas grandes cidades da Amérí ca Latina )

12. KEDY, Vitória. Implantacão do servico de arquivo e estatística em um hospital universitário. São Paulo, 1984. (Disserta ção de Nestrado à FAculdade de Saúde Pública - USP )

13. KOONTZ, HE O' DONNEL, L. Principios de administracão:uma análise das funcões administrativas. São Paulo, Pioneira,1962.

14. LEAVELL, H.R. E CLAR, E.G. Levels of application of preventive medicine. In: Preventive medicine for the doctor in his commu-

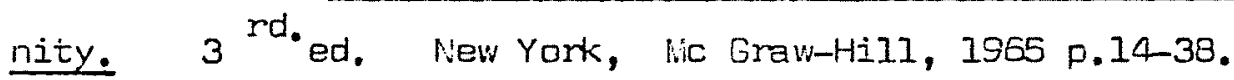

15. LEAVELL, H.R. Flanning for community health. In: LEAVELL, H.R E CLAF, E.G Preventive medicine for doctor in his community.

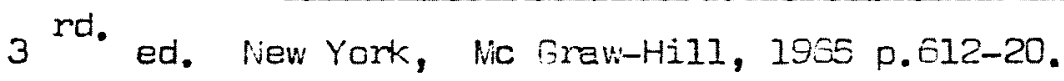

16. Nac EACHEPN, M..T. Hospital omanization and management. $3^{\text {rd. }}$ ed. Chicago Physicians Fiecord, 1957. 
17. ORGANIZAÇÃO IUNDIAL DA SAÚDE. Función de los hospitales en los programas de protección de la salud. Genebra, 1957. ( Sé rie de informes Tecnicos, no 122 )

18. ORGANIZAC̆ÃO PANALERICANA DA SAÚDE. Sistemas de salud, Washin gton, 1972. (Fublicas̃ão Científica, v. 234)

19. ORGANIZACÃO MUNDIAL DA SAÚDE. Atención primária de salud.

Genebra, 0us, 1978. (Informe de la Conferencia Internacio nal sobre- Atención Primaria de salud, AIma-Ata, UFSS, 1978 )

20. PEDROSO, Odair Pacheco. Determinacão das necessidades de leitos em hospitais gerais. Fievista Peulista de Hospitais 25 (8): 341-370, aga., 1977.

21. PEDPCSO, Odair Pacheco. Determinacão das necessidades em Ieitos de assistência hospitalar geral para o Estado de São Paulo. Revista Paulista de Hospitais 26 ( I ): 4-II, jan. 1978.

22. São Paulo ( Estado ) Secretaria da Saúde. Manual de vigilância epidemiolócica. São Paulo, 1978. 